\title{
•An Evaluation of CMIP6 Historical Simulations of the Cold Season Teleconnection between Tropical Indo-Pacific Sea Surface Temperatures and Precipitation in Southwest Asia, the Coastal Middle East, and Northern Pakistan and India ${ }^{\mathscr{O}}$
}

\author{
Mathew Barlow, ${ }^{\mathrm{a}}$ ANDrew Hoell,${ }^{\mathrm{b}}$ AND LAURIE Agel ${ }^{\mathrm{a}}$ \\ ${ }^{a}$ Department of Environmental, Earth, and Atmospheric Sciences, University of Massachusetts Lowell, Lowell, Massachusetts \\ ${ }^{\mathrm{b}}$ Physical Sciences Division, NOAA Physical Sciences Laboratory, Boulder, Colorado
}

(Manuscript received 31 December 2019, in final form 2 December 2020)

\begin{abstract}
The ability of six CMIP6 models to reproduce the observed cold season teleconnection between tropical Indo-Pacific sea surface temperatures (SSTs) and precipitation in Southwest Asia, the coastal Middle East (CME), and northern Pakistan and India (NPI) is examined. The 1979-2014 period is analyzed to maximize observations over both the tropical ocean and the regions. Nine historical simulations for the same period are examined for each model to account for the internal variability of the coupled system. The teleconnection is examined in terms of SSTs, precipitation, 200-hPa geopotential heights, and derived quantities. All the models capture some of the broadest features of the teleconnections, but there is a wide range in the ability of the models to reproduce the magnitude and details. The differences appear related to both the models' ability to capture the details of the tropical variability, including the position and strength of the precipitation anomalies in the Indo-west Pacific, and the models' ability to accurately propagate the tropically forced response into the region. The teleconnections to the CME and NPI regions on the eastern and western margins, respectively, of the strongest signal are very similar in structure and have similar results, except that the models' ability to reproduce the strength and details of the teleconnection is even more limited, consistent with their marginal locations and known influence of other modes of variability. For all three areas, the wide range in model ability to capture the leading teleconnection suggests caution in interpreting climate regional projections.
\end{abstract}

KEYWORDS: Asia; Teleconnections; Precipitation; Model evaluation/performance; ENSO

\section{Introduction}

As reviewed in Barlow et al. (2016), cold season precipitation over Southwest Asia (defined here as $40^{\circ}-70^{\circ} \mathrm{E}, 25^{\circ}-40^{\circ} \mathrm{N}$ ) is linked to tropical sea surface temperatures (SSTs) associated with the El Niño-Southern Oscillation (ENSO) phenomenon, but with larger anomalies in the central and western Pacific than in the canonical Niño-3.4 pattern. This westward-enhanced ENSO pattern is associated with tropical precipitation anomalies in the western Pacific and eastern Indian Ocean that force a circulation response that influences regional vertical motion and moisture transport. Here, we examine how well six models from phase 6 of the Coupled Model Intercomparison Project (CMIP6; Eyring et al. 2016) are able to reproduce this relationship in their historical simulations for the 1979-2014 period. Two additional regions on the eastern and western margins of the strongest signal in Southwest Asia-the coastal Middle East $\left(35^{\circ}-40^{\circ} \mathrm{E}, 30^{\circ}-35^{\circ} \mathrm{N}\right)$ and northern Pakistan and India $\left(70^{\circ}-80^{\circ} \mathrm{E}, 30^{\circ}-35^{\circ} \mathrm{N}\right)$ - are

¿ Denotes content that is immediately available upon publication as open access.

Supplemental information related to this paper is available at the Journals Online website: https://doi.org/10.1175/JCLI-D-191026.s1.

Corresponding author: mathew_barlow@uml.edu also examined to consider the sensitivity of the signal and provide information relevant to these water-stressed regions. Model ability to reproduce relevant variability for a region is key context for assessing confidence in model projections for that region.

The influence of ENSO and ENSO-related variability on Southwest Asia (SW Asia) has received a considerable amount of attention, especially in the last several years (Barlow et al. 2002; Nazemosadat and Ghasemi 2004; Mariotti et al. 2005; Syed et al. 2006; Mariotti 2007; Hoell et al. 2012, Hoell et al. 2013; Hoell and Funk 2013; Hoell et al. 2014a,b; Niranjan Kumar and Ouarda 2014; Donat et al. 2014; Hoell et al. 2015a,b; Barlow and Hoell 2015; Al Senafi and Anis 2015; Athar 2015; Kang et al. 2015; Barlow et al. 2016; Abid et al. 2016; Soltani et al. 2016; Hoell et al. 2017a,b; Cannon et al. 2017; Rana et al. 2017; Abid et al. 2018; Alizadeh-Choobari et al. 2018; Gerlitz et al. 2018, 2019; Hoell et al. 2018; Vigaud et al. 2018; Atif et al. 2019; Kamil et al. 2019; Rana et al. 2019). Figure 1 shows the observed relationship between SW Asian precipitation and the ENSO-like SSTs, upper-level circulation, and tropical precipitation, during the 1979-2014 period, as regressions. The corresponding correlations are shown in the supplemental material, along with an assessment of statistical significance. El Niño, the warm phase of ENSO, is associated with enhanced precipitation over SW Asia, whereas La Niña, the cold phase, is associated with suppressed precipitation and drought over SW Asia. The state of the west Pacific during ENSO events appears to be important to the atmospheric response (Barlow et al. 2002; Hoerling and Kumar 2003; Hoell 


\section{a) Z200, Precip Regressions}

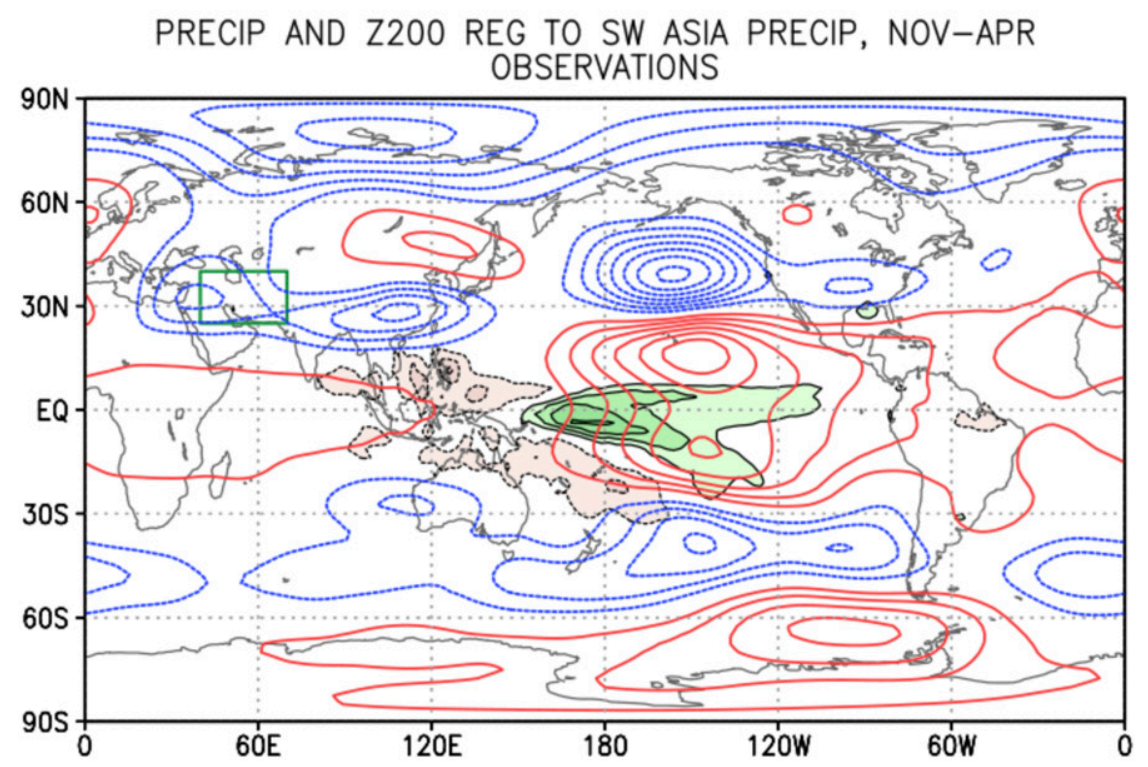

\section{b) SST Regression}

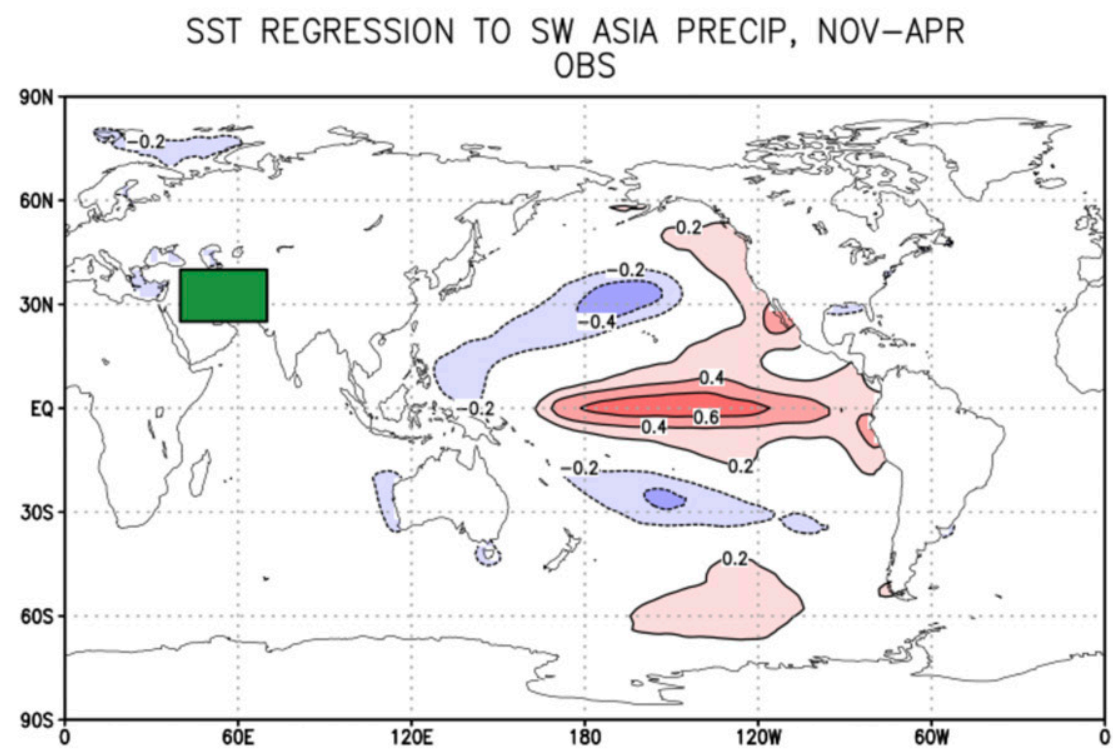

$\mathrm{Cl}: 0.2$

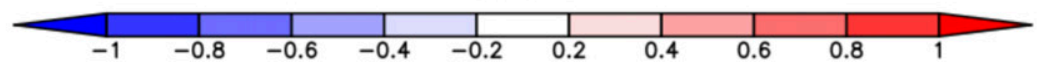

FIG. 1. Observed teleconnections to SW Asian precipitation. (a) 200-hPa heights and precipitation regressed to precipitation over SW Asia (green box). (b) SST regressions. November-April seasonal means are used for the 1979-2014 period. The green box denotes the area over which precipitation is averaged for SW Asia $\left(40^{\circ}-70^{\circ} \mathrm{E}, 25^{\circ}-40^{\circ} \mathrm{N}\right)$. The contour interval for precipitation is $0.6 \mathrm{~mm} \mathrm{day}^{-1}$; for heights, $5 \mathrm{~m}$; and for SSTs, $0.2^{\circ} \mathrm{C}$. 
and Funk 2013), although it is not yet clear whether this is an intrinsic part of the ENSO variability or perhaps associated with decadal variability or climate change (Barlow and Hoell 2015).

The ENSO-related variability includes precipitation anomalies in the tropical Indo-Pacific that are associated with deeptropospheric diabatic heating anomalies that can induce large-scale circulation responses. There are two known pathways for the tropical variability to influence SW Asia. The first is through a more local teleconnection, in which Rossby waves develop poleward and westward of the diabatic heating anomalies (Barlow et al. 2002, Barlow et al. 2007, Hoell et al. 2012), consistent with a Gill-Matsuno response (Gill 1980; Matsuno 1966) modified by the mean wind [Barlow 2012; see also Ting and Sardeshmukh (1993) and Ting and Yu (1998)]. The second pathway is part of a hemispheric teleconnection (Hoell et al. 2013) in which stationary Rossby waves with northeastward group velocity originate over the tropical central Pacific (Shaman and Tziperman 2005; Niranjan Kumar et al. 2016). The remotely forced circulation anomalies over the region can modify local precipitation through changes to both vertical velocity (Hoell et al. 2012, 2014b) and moisture flux (Mariotti 2007; Barlow and Tippett 2008; Hoell et al. 2014b).

The SW Asian domain used here has been identified in previous research as closely connected to the tropical SSTs but does not completely capture the signal in the region. There is also evidence for an ENSO influence on the western margin of the region, in the coastal Middle East, although the signal does not appear to be present prior to 1975 (Price et al. 1998). The reasons for a possibly nonstationary influence on the region from ENSO are not clear, although the greater distance from the tropical forcing may be a factor, as well as the relative importance of other modes of variability such as the NAO, which is known to have an important influence on the region (e.g., Cullen et al. 2002; Mann 2002; Black 2012). On the eastern margin of the signal, there is also evidence for an ENSO influence that is stronger in the more recent period (Yadav et al. 2009). Consideration of these two regions provides a fuller picture of the observed teleconnection and model behavior in the region.

The aim of this study is to assess the ability of current climate models to reproduce these relationships. The post-1979 period is considered, to coincide with the satellite observational period, which provides consistent coverage of oceanic precipitation and additional information for the data-sparse region of SW Asia (Hoell et al. 2015b, 2017a). Given both internal atmospheric variability and variability in the coupled system, the teleconnections in even a perfect model would not be expected to match observations in every simulation. Here nine simulations are considered for each model, and, depending on context, either the closest match with observations or the average over all simulations (ensemble average) is used, to account for the expected differences in internal variability between simulations. As context for the analysis of interannual variability, the models' simulations of the regional seasonal cycle of precipitation are also assessed. The remainder of the paper is organized as follows: the data sources are described in section 2; the models' representations of the precipitation seasonal cycle and teleconnections for the three regions, as well as the associated tropical variability and jet stream waveguides, are investigated in section 3; and a summary and discussion are provided in section 4 .

\section{Data}

The data used in this study involve both observed estimates, described in section $2 \mathrm{a}$, and model simulations, described in section $2 \mathrm{~b}$. While observational data quality and coverage is a concern for Southwest Asia, even in the satellite era, the datasets used here have been shown in previous studies to capture the large-scale relationships in the post-1979 period (e.g., Barlow et al. 2016, and references therein). The influence of data limitations on characterizing the observed variability in the pre-1979 period is still an area of active investigation.

\section{a. Observed estimates}

The GPCP V2 dataset (Adler et al. 2003), a blend of satellite data and surface rain gauge observations, is used for precipitation. The ERSST5 dataset (Huang et al. 2017) is used for SSTs.

The NCEP-NCAR reanalysis dataset (Kalnay et al. 1996) is used for $200-\mathrm{hPa}$ geopotential height and the derived quantities of geostrophic zonal wind and meridional derivatives thereof.

\section{b. Model simulations}

Nine historical simulations for the 1979-2014 period are considered for six CMIP6 (Eyring et al. 2016) models: CanESM5 (Swart et al. 2019), CESM2 (Danabasoglu et al. 2020), CNRM-CM6-1 (Voldoire et al. 2019), GISS-E2-1-H (Kelley et al. 2020), MIROC6 (Tatebe et al. 2019), and MPIESM1-2-HR (Gutjahr et al. 2019). A summary of the spatial resolution of the models is provided in Table 1, taken from the CMIP6 model description data file available at https:// raw.githubusercontent.com/WCRP-CMIP/CMIP6_CVs/master/ CMIP6_source_id.json.

\section{Results}

The models' representations of the regional seasonal cycles of precipitation are examined in section $3 \mathrm{a}$ to provide context for the consideration of variability. The representation of teleconnections is then examined in following subsections, in terms of teleconnections to SW Asian precipitation (section 3b), teleconnections to the related tropical SSTs (section 3c), and tropical convection in eastern Indian Ocean (section 3d), model reproduction of the zonal jets and associated waveguide (section 3e), and, finally, the teleconnections to the coastal Middle East and northern Pakistan and India (section 3f).

\section{a. Regional seasonal cycles}

A comparison of the models' ensemble-average simulation (black) of the precipitation seasonal cycle with observations (green) for the three regions is shown in Fig. 2. Individual model runs are shown in light gray to verify that the seasonal 
TABLE 1. Spatial resolution of the atmospheric and oceanic components of the six CMIP6 models used in the study. The horizontal resolution is given in terms of the nominal resolution $(\mathrm{km})$ to allow for easy comparison; for exact model grid type and resolution information, please see the model references given in the text.

\begin{tabular}{lcccc}
\hline \hline \multicolumn{1}{c}{ Model } & $\begin{array}{c}\text { Atmosphere horizontal } \\
\text { resolution }(\mathrm{km})\end{array}$ & $\begin{array}{c}\text { Atmosphere vertical } \\
\text { levels }\end{array}$ & $\begin{array}{c}\text { Ocean horizontal } \\
\text { resolution }(\mathrm{km})\end{array}$ & $\begin{array}{c}\text { Ocean vertical } \\
\text { levels }\end{array}$ \\
\hline CanESM5 & 500 & 49 & 100 & 45 \\
CESM2 & 100 & 32 & 100 & 62 \\
CNRM-CM6-1 & 250 & 91 & 100 & 75 \\
GISS-E2-1-H & 250 & 40 & 100 & 26 \\
MIROC6 & 250 & 81 & 100 & 63 \\
MPI-ESM1-2-HR & 100 & 95 & 50 & 40 \\
\hline
\end{tabular}

cycle features discussed here are well captured in the 35-yr period of the individual runs. Precipitation in the region primarily occurs in the November-April boreal cold season due to synoptic storms (extratropical cyclones), although there is some warm season precipitation associated with the summer monsoon in Pakistan and southeastern Afghanistan, and with the intertropical convergence zone (ITCZ) along the southern coast of the Arabian Peninsula (Barlow et al. 2016). The models generally capture the wet cold season-dry warm season distinction in both SW Asia (Fig. 2, left column) and the coastal Middle East (Fig. 2, middle column). There are some issues with the timing of the seasonal peak (most of the models have a maximum too late in the spring) and the amplitude (most prominently, the cold season values in the CanESM are substantially lower than observations for both regions), and several of the models have large differences (more than a factor of 2) from observations for individual months. The northern Pakistan and India region (Fig. 2, right column) appears to be the most challenging for simulation, with none of the models capturing the observed ratio of warm season to cold season precipitation, and two of the models (CanESM5 and GISS-E2) failing to capture any of the monsoonal signal in the summer. Although not considered further in this study, there are substantial hydrological implications associated with these issues for all three regions in terms of the associated simulation (either directly or with an offline model) of seasonal snowpack, snowmelt, and runoff amplitude and timing.

\section{b. Teleconnections to SW Asian precipitation}

The correlations between SW Asian precipitation and SSTs are shown for both observations and the six CMIP6 models in Fig. 3. For each model, the simulation (out of nine, for each model) with the closest match to observed SSTs, in terms of spatial correlation, is shown. Even in a perfect model, we would expect run-to-run variations in both the internal atmospheric variability that acts as noise to the teleconnection as well as in the ENSO-related variability that drives the teleconnection itself. Therefore, the model simulation with the closest correspondence to observations provides the most apt comparison. To provide an overview of the general behavior of the models, the distribution of spatial correlations for all simulations of each model is shown in Fig. 4, and the ensembleaverage response is considered in section $3 \mathrm{c}$. Some models, such as the CNRM-CM6-1, have a large range in how closely an individual run matches observations, whereas others, such as
CESM2, have most of the individual run matching observations fairly closely (spatial correlations greater than 0.6).

All six models capture the relationship in the broadest sense of having positive SST correlations in the central equatorial Pacific and negative correlations in the western Pacific, but with a wide range of differences among the models in the strength of the correlation. Only two of the models, CESM2 and MIROC6, have substantial areas of correlations greater than 0.6 in the central equatorial Pacific, in correspondence with observations. In the area of highest correlation $\left(170^{\circ} \mathrm{E}-\right.$ $120^{\circ} \mathrm{W}, 5^{\circ} \mathrm{S}-5^{\circ} \mathrm{N}$ ) where the average correlation in observations is 0.65 , the average correlation in the models ranges by more than $40 \%$ from 0.40 in the MPI-ESM1 to 0.67 in the CESM2. Based on Monte Carlo random resampling, the SST correlations in all the models are significantly different from the correlations in observations at the $5 \%$ level for the domain shown. Individual field significance values and local significance figures are shown for the correlations to all fields in all the models in the online supplemental material. The features discussed below are all locally significant at the $5 \%$ level.

The CESM2 has the closest similarity to the observational pattern as well as the largest positive correlations in the central Pacific and the largest negative correlations in the western Pacific. However, even for the CESM2, there are notable differences from observations in the Indian Ocean as well as more minor differences in the Pacific. The MIROC6 is more like observations in the Indian Ocean but correlations are too weak in the Pacific and too strong in the South Atlantic. The other models have a range of differences but, overall, do not have large enough correlations in the central and western Pacific.

Both the observational data quality and the number of simulations for each model impose limitations on this analysis. As noted in the introduction and discussed further in the previous section, limited precipitation data availability in SW Asia complicates observational analysis in the pre-1979 period, which limits our current understanding of how much the strength of the teleconnection varies decadally in observations (e.g., Hoell et al. 2015b; Rana et al. 2019). As a result, it is not clear at this point what spread of differences between simulations is most realistic and, relatedly, how many simulations per model are needed to encompass observations. However, even with these limitations, it is clear that, for SST correlations based on nine simulations, some models closely reproduce the observed relationship in both pattern and magnitude (in terms of a spatial pattern correlation for SST $>0.9$ and an SST 


\section{Precipitation Seasonal Cycles}
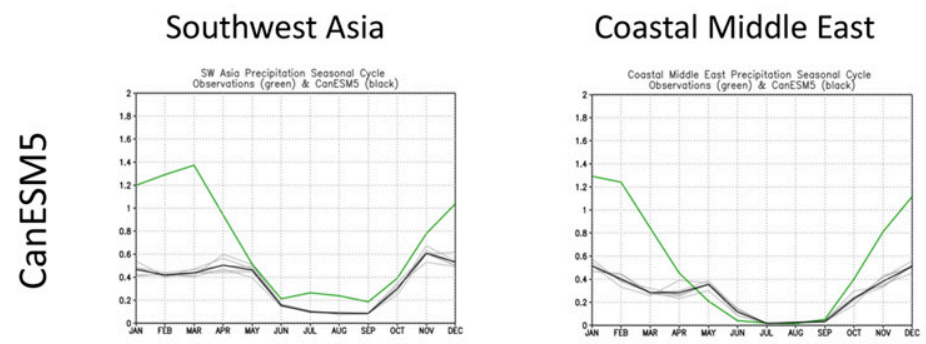

\section{N. Pakistan and India}
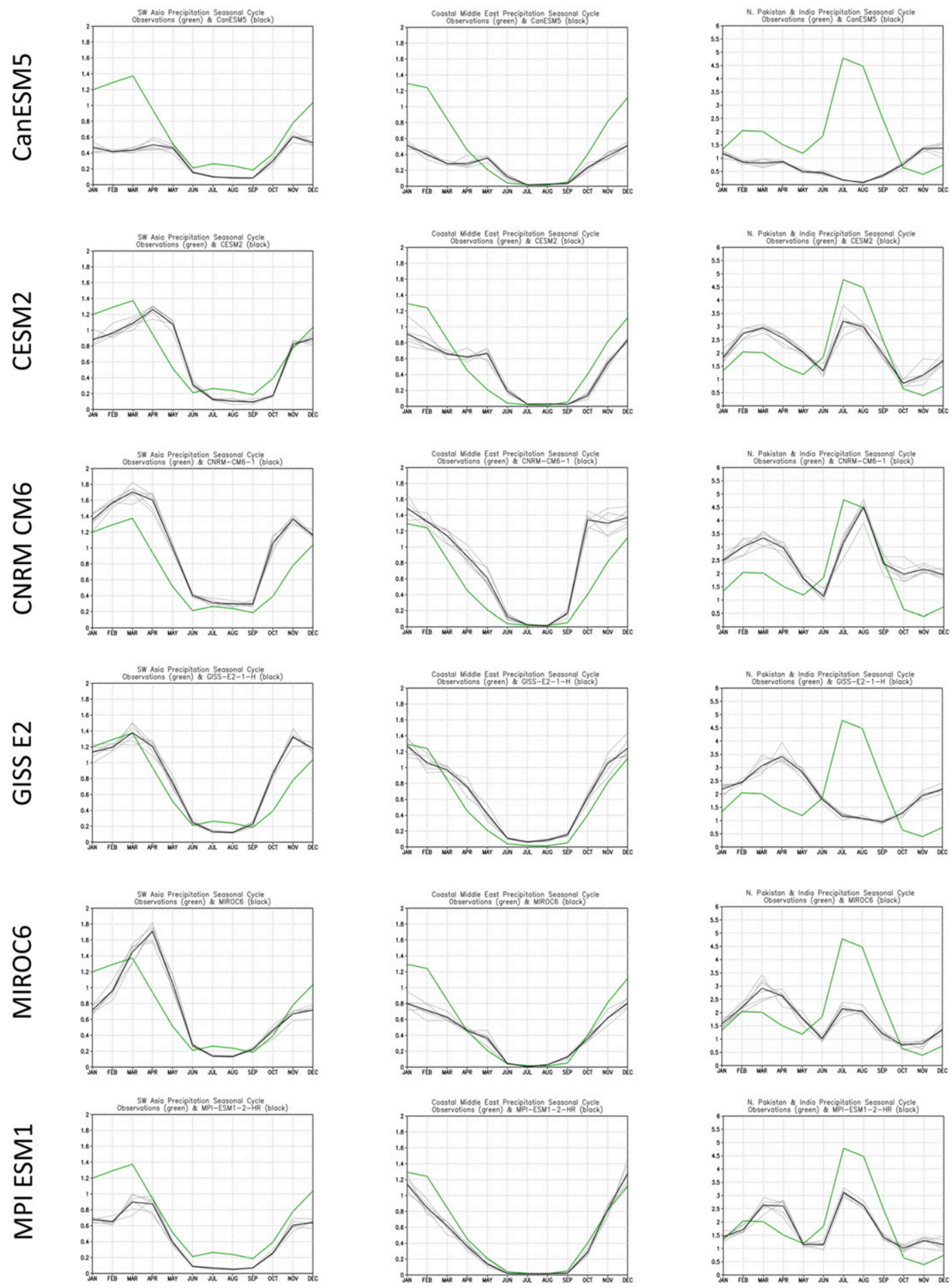

FIG. 2. Modeled seasonal cycles. Seasonal cycles in the six models (rows) for the three regions (columns). Observations are shown in green and the model ensemble averages in black, with individual runs in light gray. The unit for precipitation is mm day ${ }^{-1}$. 


\section{a) OBS}

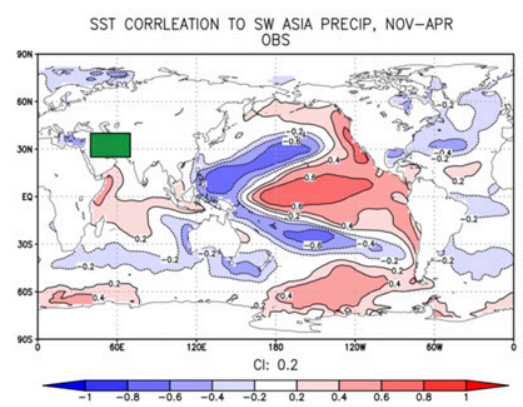

\section{b) CanESM5}

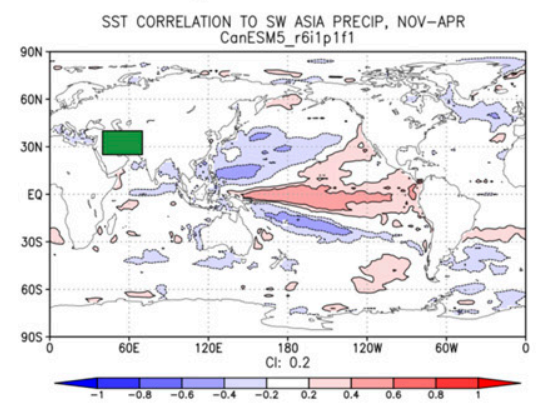

\section{c) CESM2}

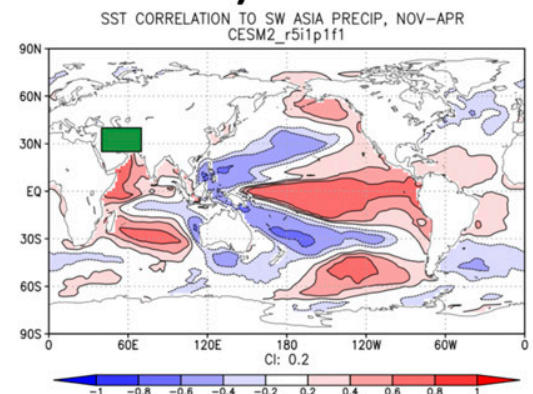

d) CNRM-CM6-1

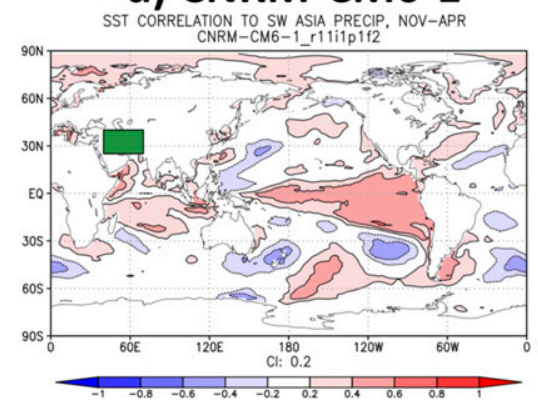

e) GISS-E2-1-H

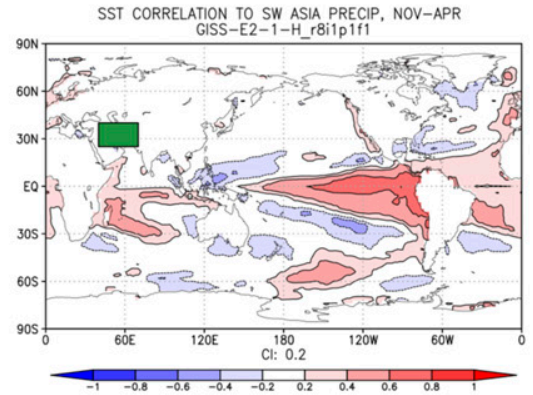

f) MIROC6

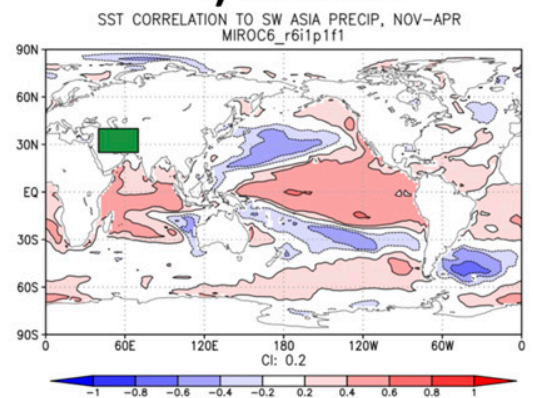

g) MPI-ESM1-2-HR

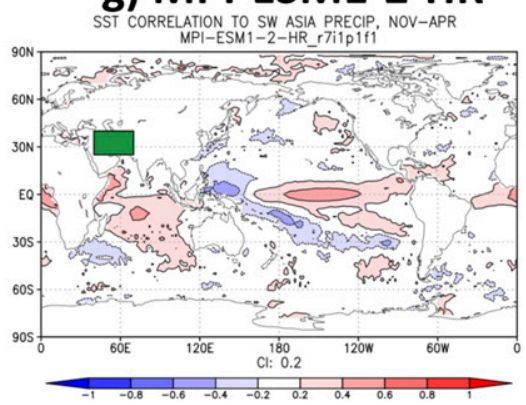

FIG. 3. Model-observation comparison for SSTs. SST correlations to SW Asian precipitation are shown for (a) observations and (b)-(g) models. For each model, the simulation (out of nine, for each model) with the closest match is shown. The contour interval is 0.2 for all panels. 


\section{a) CanESM5}

CanESM5 SST Correlations

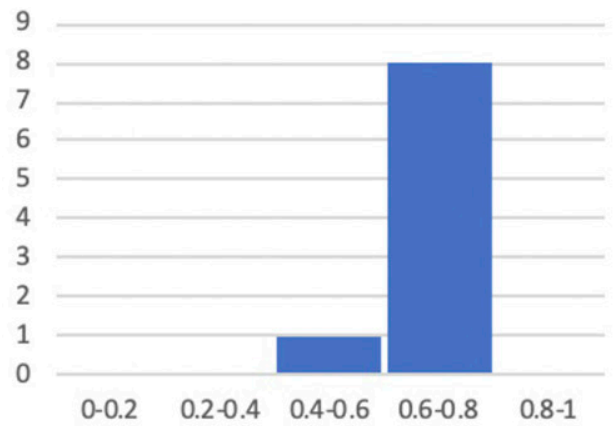

b) CESM2

CESM2 SST Correlations

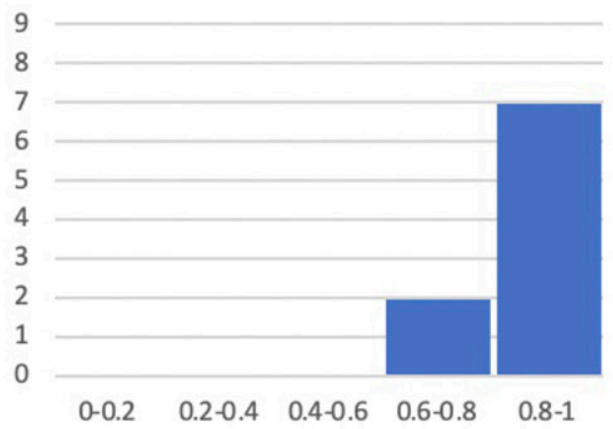

c) CNRM-CM6-1

\section{CNRM-CM6-1 SST Correlations}

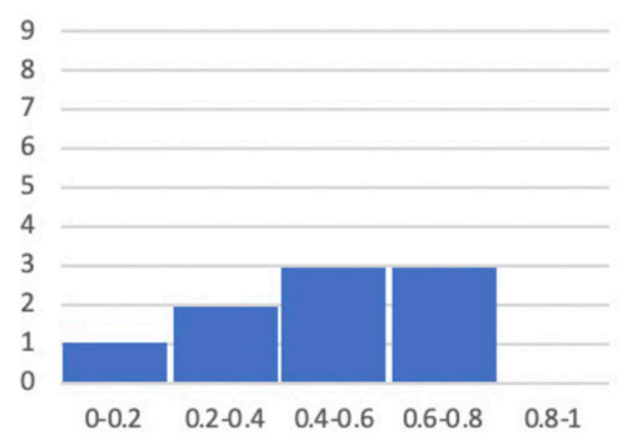

d) GISS-E2-1-H

GISS-E2-1-H SST Correlations

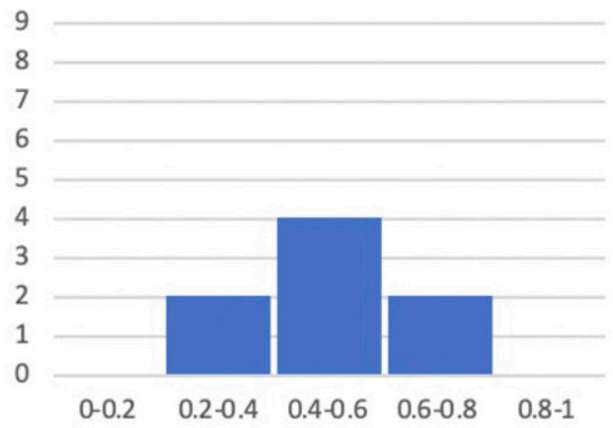

e) MIROC6

MIROC6 SST Correlations

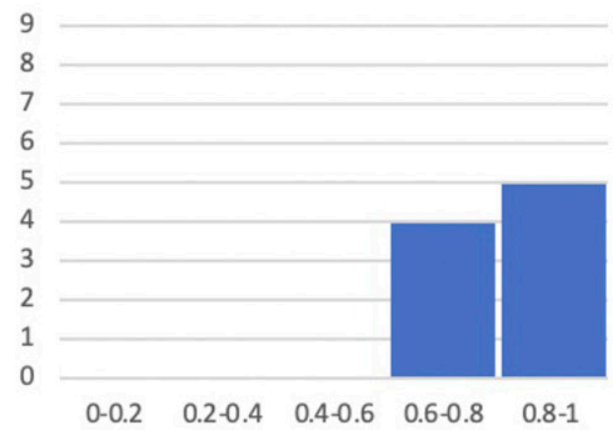

f) MPI-ESM1-2-HR

MPI-ESM1-2-HR SST Correlations

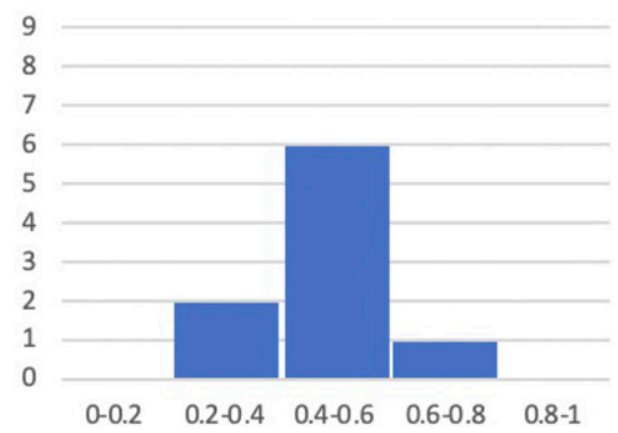

FIG. 4. Histograms of SST pattern correlations. The histograms of the spatial correlations between the model SST patterns and the observed pattern for each of the nine simulations per model. 
maximum tropical Pacific correlation $>0.75$ ) while others have a much weaker relationship.

Consideration of precipitation and upper-level circulation, shown in Fig. 5, provides an additional perspective on the teleconnection. The upper-level circulation is shown in terms of 200-hPa geopotential heights and the relationship is shown in terms of a regression rather than a correlation, to emphasize the physical relationship between the two fields. The same individual simulations - the closest SST matches-from Fig. 3 are shown in Fig. 5.

Further differences are seen between the models even with the closest SST matches: both the tropical precipitation and upper-level height anomalies are larger in the models than in observations. However, there is a good agreement in the general features between the CESM2 and the MIROC6 models and observations. While the CESM2 SSTs are a closer match to observations than the MIROC6, the tropical precipitation anomalies in MIROC6 are more similar to observations.

The distribution of SW Asian seasonal precipitation anomalies for the simulations with the best SST matches are shown in Fig. 6. Very broadly, the modeled range of values is similar to observations. However, there are some differences: CanESM5 has too narrow a range of variability, and some of the models have extreme values that are considerably outside the observed range, although the irregularity of the histograms suggests that the 36-yr period considered here is insufficient to fully describe the distribution.

\section{c. Model teleconnections to the SW Asia-related tropical SSTS}

The correlations between SW Asia and SSTs in Fig. 2 show that some models produce only a weak correlation to tropical Pacific SSTs. This may be due to a poor representation of the tropical variability itself, problems in the propagation of the response to the tropical forcing, or both. Here, we focus on the models' ability to reproduce the tropical variability.

To focus on tropical SST variability, we construct an SST index that captures the tropical SST signal relevant to SW Asia. The index is calculated by taking the observed SST pattern (Fig. 1b), multiplying it by the monthly SSTs, seasonally averaging, and then spatially averaging the result over the tropics $\left(0^{\circ}-360^{\circ}, 23.5^{\circ} \mathrm{S}-23.5^{\circ} \mathrm{N}\right)$. The result is a monthly tropical SST index, analogous in some sense to traditional SST indices like Niño-3.4 but focusing on the SST pattern directly relevant to SW Asia. The results are not sensitive to modest changes in the parameters of the calculation. The resulting index is closely related to the standard Niño-3.4 ENSO index; the correlation between the two indices is 0.91 and the SST pattern, as will be seen, is very similar, but with stronger negative values in the western Pacific and slightly weaker positive values in the eastern Pacific than the Niño-3.4 SST pattern.

Can such an index, based solely on tropical SSTs, capture the teleconnection of interest? Figure 7 shows the precipitation and circulation regressions to SW Asia in the upper panel and to the tropical SST index in the lower panel. Although there are some minor differences, the pattern is closely reproduced in both structure and magnitude, validating the tropical SST index and further emphasizing the importance of tropical SSTs for SW Asian precipitation. The precipitation relationship is shown as a regression to highlight the tropical forcing; precipitation correlations are very similar as well.

Figure 8 shows the observation and model SST correlation to the tropical SST index, using the closest model match, as before. In contrast to the model's representation of the SST correlations to SW Asian precipitation (Fig. 3), all the models reproduce a magnitude of response similar to observations, although there are a range of modest differences in pattern. Even the models that produce a much weaker teleconnection than observations are still producing a strong expression of the tropical SST variability. For example, the MPI-ESM1-2-HR maximum SST correlation to the tropical SST index is approximately 0.8 (Fig. 8g), consistent with observations (Fig. 8a), while its maximum correlation to SW Asian precipitation is approximately 0.4 , (Fig. $3 g$ ), only about two-thirds the value of observations (Fig. 3a).

The average precipitation and upper-level circulation response for all simulations for each model (the ensemble average response) regressed to the tropical SST index is shown in Fig. 9, to focus on the SST-driven response. Focusing on the SST variability associated with the tropical SST index, as here, instead of the correlations to SW Asian precipitation, as before, shows a vigorous response in tropical Pacific precipitation in all models. Interestingly, the MPI-ESM1-2-HR model, which has one of the weakest SST correlations to SW Asia (Fig. 3), has the most realistic tropical precipitation regression to the tropical SST index (Fig. 8), whereas the tropical precipitation anomalies in the other models tend to be more zonally elongated relative to observations.

However, despite the close correspondence in tropical Pacific precipitation anomalies for the MPI model, the upperlevel circulation response through southern Asia into SW Asia is extremely weak, consistent with the modest correlations to SW Asian precipitation. This is apparent in several of the models: vigorous tropical precipitation anomalies, including the negative anomalies in the western Pacific identified as particularly important in previous work, but a modest or weak circulation response over Southeast Asia and very weak or nonexistent propagation into SW Asia. It may be that the midlatitude response is very sensitive to the exact location and extent of the negative anomalies; for example, the negative anomalies in the MPI model do not extend westward much beyond $120^{\circ} \mathrm{E}$, whereas in observations and other models the negative anomalies extend into the eastern Indian Ocean. This is considered further in the next section. Additionally, any issues with the model representation of the local jet stream structure may also create problems in correctly reproducing the remote response to the tropical precipitation anomalies, which is considered in section $3 \mathrm{e}$.

\section{d. Model teleconnections to tropical convection in the eastern Indian Ocean}

Convection in the tropical eastern Indian Ocean $\left(90^{\circ}-100^{\circ} \mathrm{E}\right.$, $\left.10^{\circ} \mathrm{S}-15^{\circ} \mathrm{N}\right)$ has been identified as an important component of the tropical part of teleconnection in Barlow et al. (2002), who referred to this area as the "IPX" region. Figure 10 shows a 
a) OBS

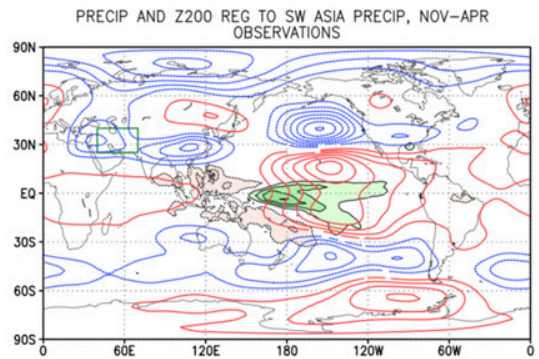

\section{b) CanESM5}

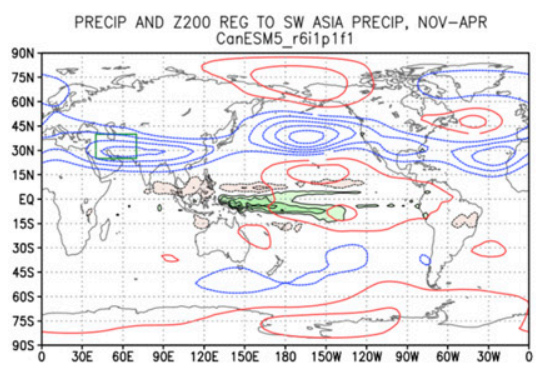

c) CESM2

PRECIP AND Z200 REG TO SW ASIA PRECIP, NOV-APR

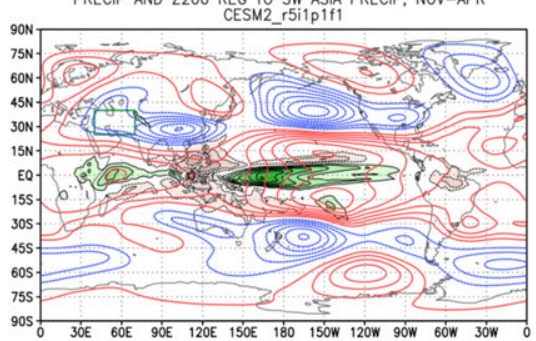

\section{d) CNRM-CM6-1}

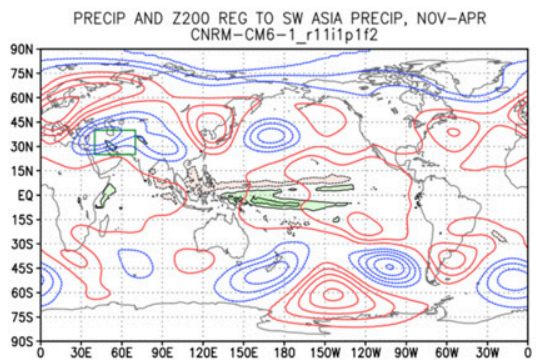

e) GISS-E2-1-H

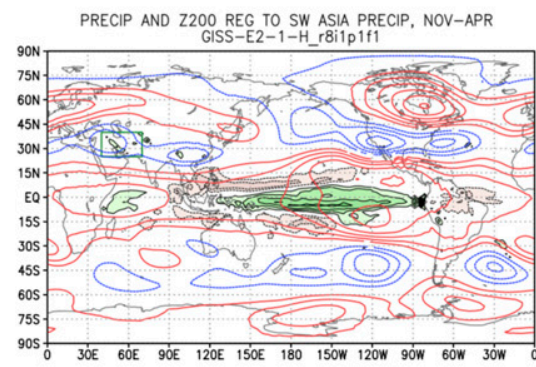

f) MIROC6

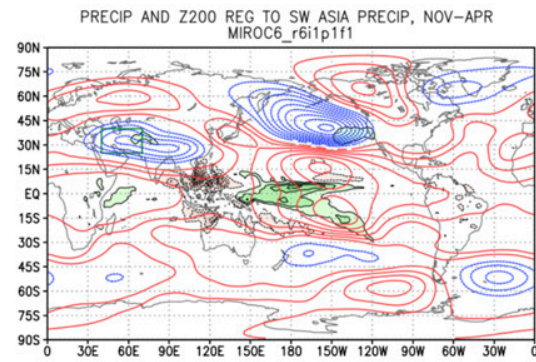

g) MPI-ESM1-2-HR

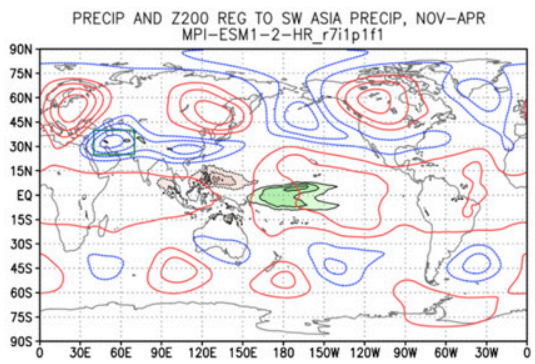

FIG. 5. Model-observation comparison for precipitation and 200-hPa heights. Precipitation and 200-hPa height regressions to SW Asian precipitation are shown for (a) observations and (b) $-(\mathrm{g})$ models. For each model, the simulation (out of nine, for each model) with the closest match is shown. The contour interval is $0.6 \mathrm{~mm} \mathrm{day}^{-1}$ for precipitation, with green and brown shading for positive and negative anomalies, respectively, and $5 \mathrm{~m}$ for heights, with red and blue contours for positive and negative. 


\section{a) OBS}

Histogram of SW Asia Precip

Observations

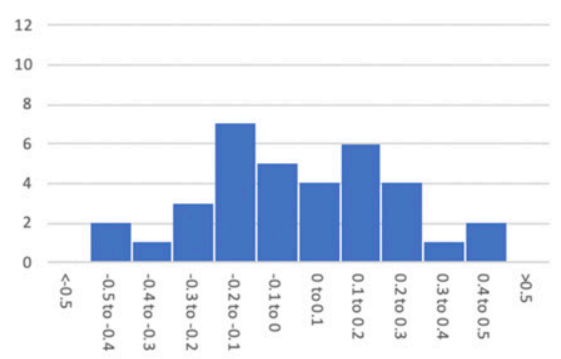

\section{b) CanESM5}

Histogram of SW Asia Precip CanESM5 r6

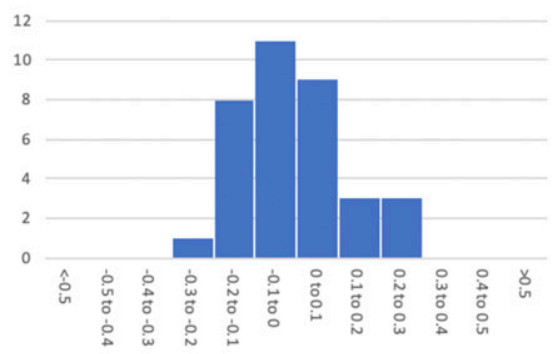

\section{c) CESM2}

Histogram of SW Asia Precip CESM2 r5

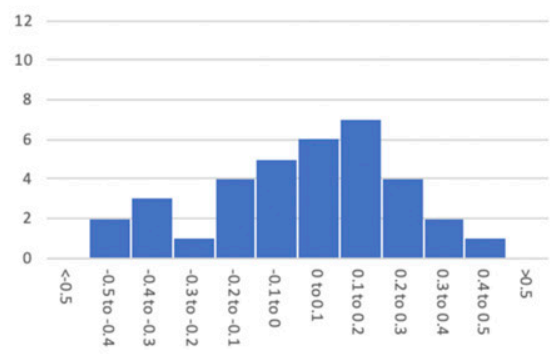

d) CNRM-CM6-1

Histogram of SW Asia Precip CNRM-CM6-1 r11

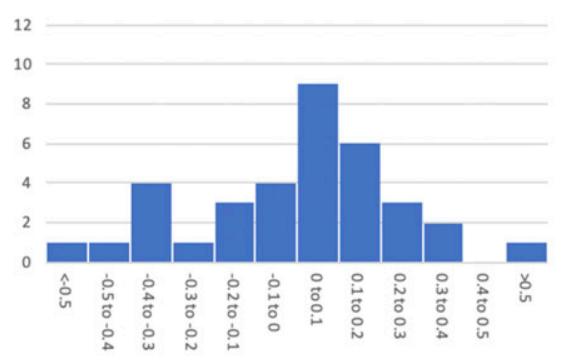

e) GISS-E2-1-H

Histogram of SW Asia Precip GISS-E2-1-H r8

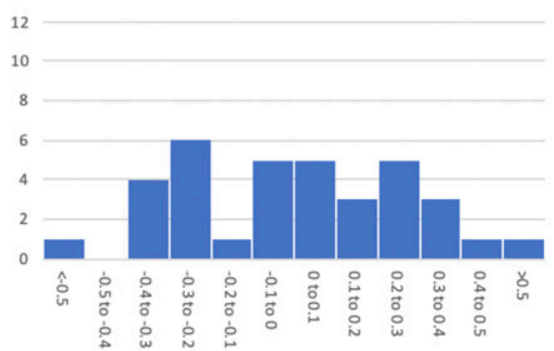

f) MIROC6

Histogram of SW Asia Precip MIROC6 r6

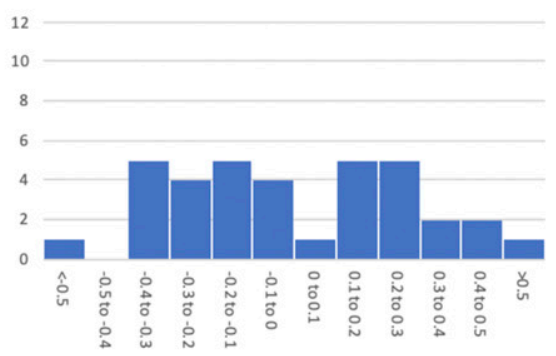

g) MPI-ESM1-2-HR

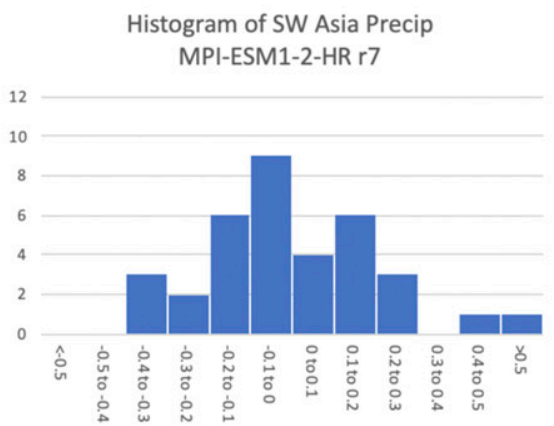

FIG. 6. Histograms of SW Asian seasonal precipitation anomalies $\left(\mathrm{mm} \mathrm{day}^{-1}\right)$. The distribution of seasonal SW Asian precipitation anomalies are shown for observations and for the model simulation with the closest match to observed SSTs, as in Figs. 3 and 5. 


\section{a) Regression to SW Asia Precip}

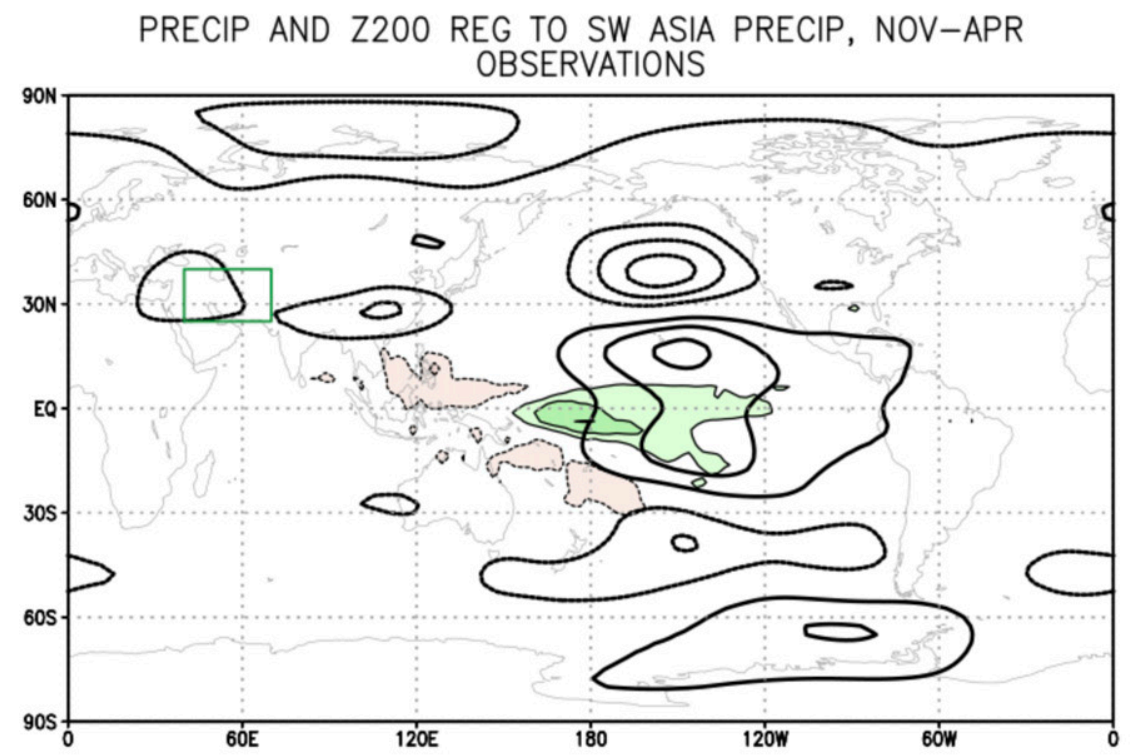

\section{b) Regression to SST Index}



FIG. 7. Validation of the tropical SST index, showing the regression of precipitation and 200$\mathrm{hPa}$ heights to (a) SW Asian precipitation and (b) the tropical SST index. The SST index is made by multiplying the observed SST regression to SW Asia precipitation (Fig. 1b) and the SST anomalies for each season, and then spatially averaging over the tropics $\left(0^{\circ}-360^{\circ}\right.$ longitude, $\left.23.5^{\circ} \mathrm{S}-23.5^{\circ} \mathrm{N}\right)$. The contour interval is $0.8 \mathrm{~mm}$ day $^{-1}$ for precipitation, with green and brown shading for positive and negative anomalies, respectively, and $10 \mathrm{~m}$ for heights, with red and blue contours. 


\section{a) OBS}

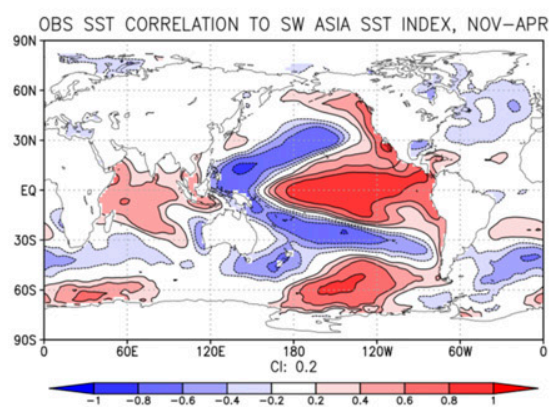

b) CanESM5

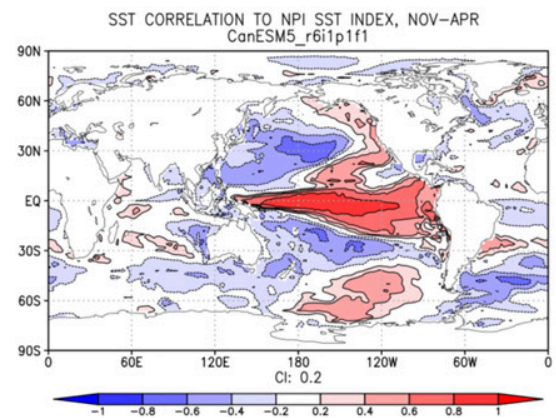

c) CESM2

SST CORRELATION TO SW ASIA SST INDEX, NOV-APR

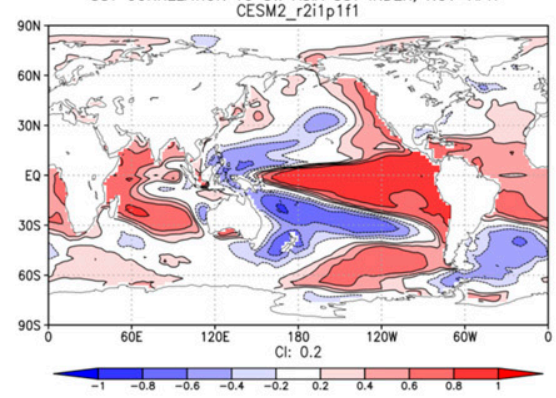

d) CNRM-CM6-1

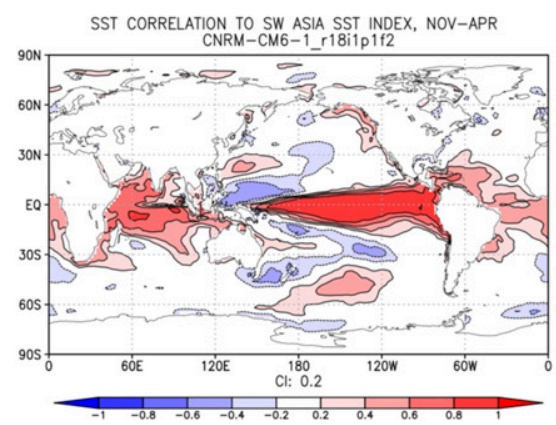

e) GISS-E2-1-H

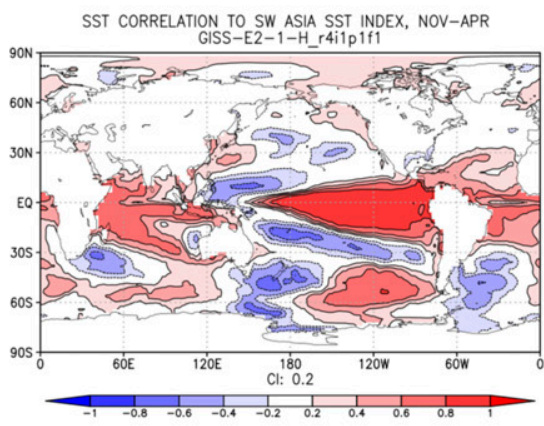

f) MIROC6

SST CORRELATION TO SW ASIA SST INDEX, NOV-APR

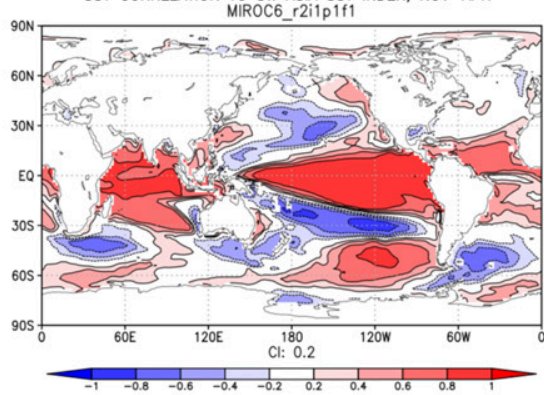

g) MPI-ESM1-2-HR

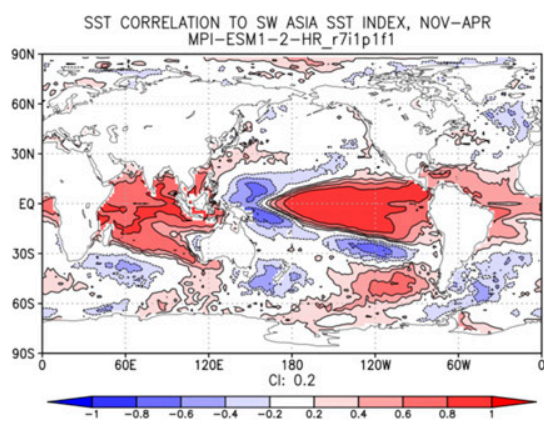

FIG. 8. Model-observation comparison for SSTs, based on tropical SST index. SST correlations to the SST index are shown for (a) observations and (b)-(g) models. For each model, the simulation (out of nine, for each model) with the closest match is shown. The contour interval is 0.2 . 


\section{a) CanESM5}

PRECIP AND Z200 REG TO SST INDEX, NOV-APR

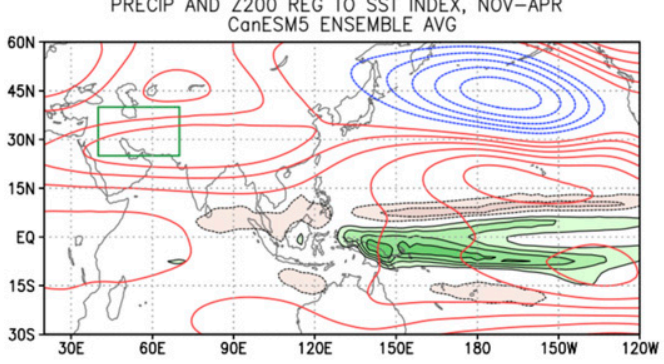

b) CESM2

PRECIP AND Z200 REG TO SST INDEX, NOV-APR

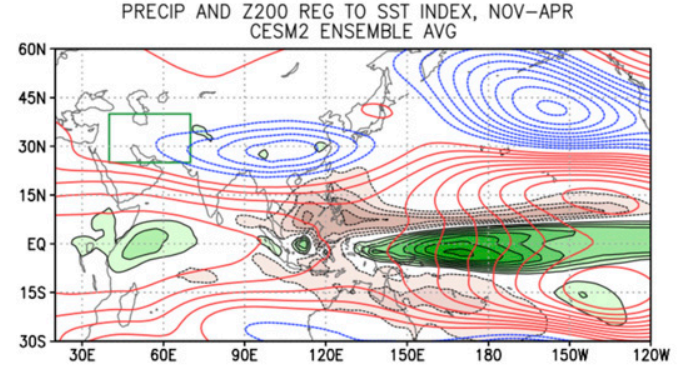

c) CNRM-CM6-1

PRECIP AND Z200 REG TO SST INDEX, NOV-APR

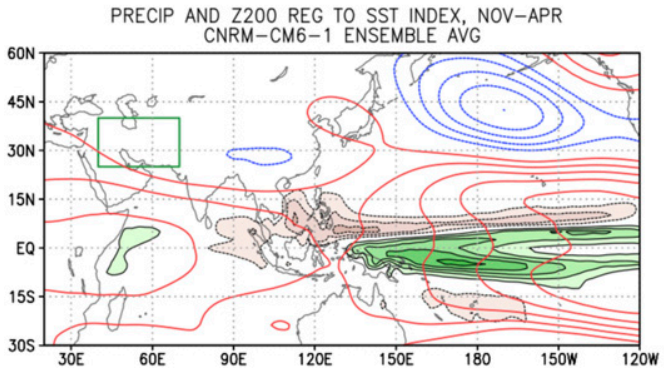

d) GISS-E2-1-H

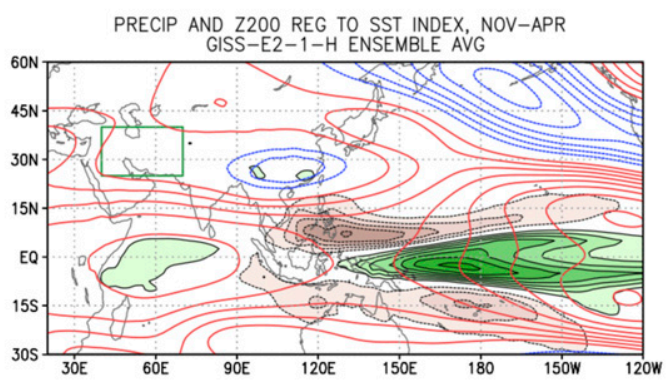

e) MIROC6

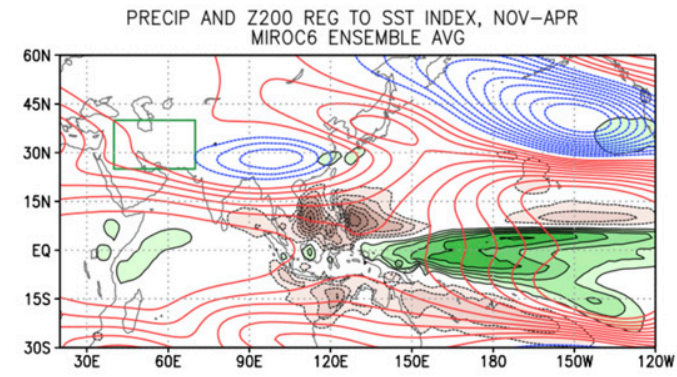

f) MPI-ESM1-2-HR

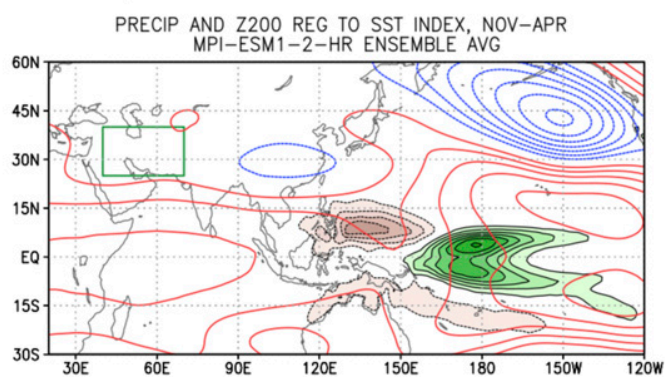

FIG. 9. Model ensemble average regressed to tropical SST index. Ensemble-average regressions to the SST index are shown for the six models. The contour interval is $0.6 \mathrm{~mm} \mathrm{day}^{-1}$ for precipitation, with green and brown shading for positive and negative anomalies, respectively, and $5 \mathrm{~m}$ for heights, with red and blue contours for positive and negative.

comparison between the observations and the models for the regressions to this region. In this case, monthly rather than seasonal data are used to focus more on the response to the local variability rather than to the larger-scale seasonal variability. Not all models extend tropical precipitation anomalies into this region as part of their tropical response, so analyzing this region provides some insight into the models midlatitude response even for models that do not capture the full tropical response well. Previous experiments with models of varying complexity (Barlow et al. 2002, 2007; Barlow 2012) reproduce the circulation response and influence on precipitation over SW Asia as a response to tropical forcing in the IPX region, with an important influence from the mean wind (Barlow 2012). Most of the models considered here have a substantially weaker circulation response associated with the IPX region than observations, although with a considerable range in model behavior. The MPI-ESM1-2-HR response is closest in strength to observations. This is particularly interesting given that it has one of the weakest connections between SW Asian precipitation and tropical SSTs (Fig. 3g). As the ensemble-average teleconnection to the tropical SST index for that model (Fig. 9f) shows little precipitation signal in the eastern Indian Ocean, it suggests that the leading factor in that model's difficulty in capturing the SW Asian teleconnection may be in its representation of the tropical signal.

\section{e. Jet stream and waveguide}

The potential vorticity gradient of the jet stream is an important factor in the remote response to tropical forcing as it provides a waveguide for the propagation of the Rossby 


\section{a) OBS}

PRECIP AND Z200 MON COR TO IPX PRECIP, NOV-APR

\section{b) CanESM5}

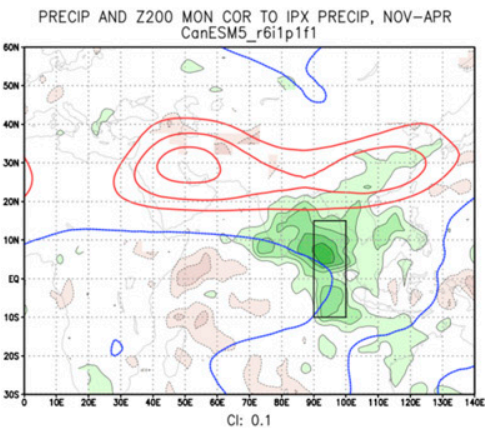

c) CESM2

PRECIP AND Z200 MON COR TO IPX PRECIP, NOV-APR

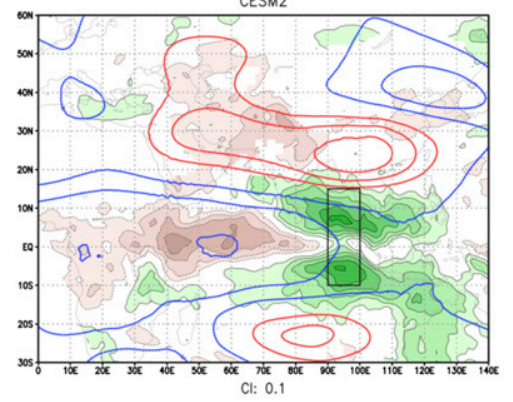

d) CNRM-CM6-1

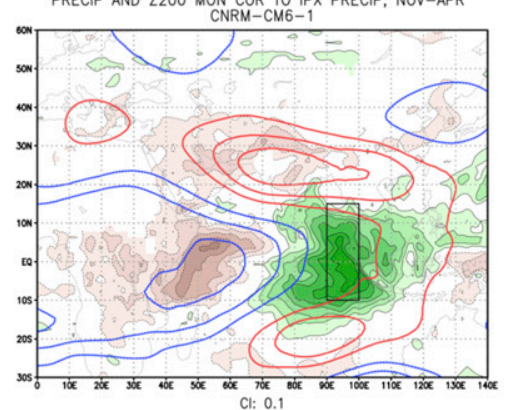

e) GISS-E2-1-H

PRECIP AND Z200 MON COR TO IPX PRECIP, NOV-APR

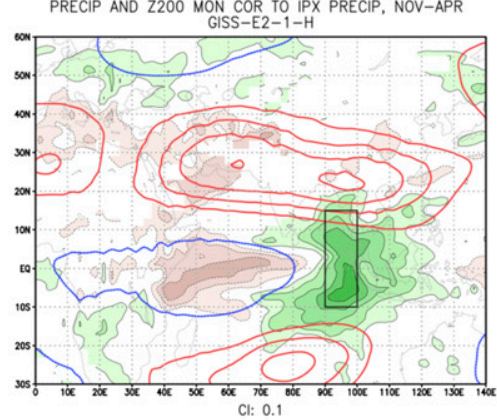

f) MIROC6

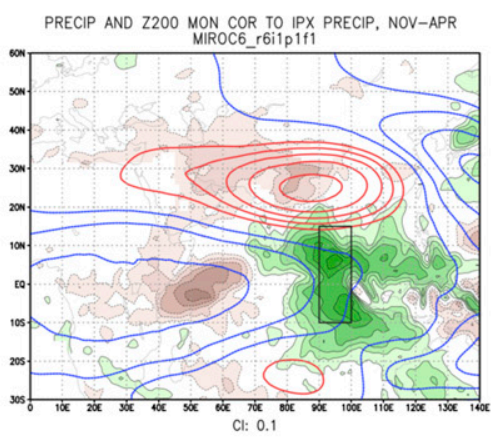

g) MPI-ESM1-2-HR

PRECIP AND Z200 MON COR TO IPX PRECIP, NOV-APR

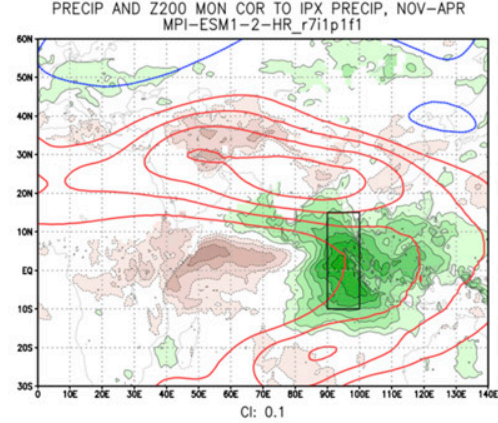

FIG. 10. Correlations to the IPX region for precipitation and 200-hPa heights. Precipitation and 200-hPa height correlations to the IPX region (black box: $90^{\circ}-100^{\circ} \mathrm{E}, 10^{\circ} \mathrm{S}-15^{\circ} \mathrm{N}$ ) are shown for (a) observations and (b)-(g) models. For each model, the simulation (out of nine, for each model) with the closest match is shown. The contour interval is 0.1 for both precipitation and heights. 
wave response to tropical forcing (Hoskins and Ambrizzi 1993) as well as an area where divergent outflow from tropical convection can be converted into a subtropical vorticity source (Sardeshmukh and Hoskins 1988). The models' simulation of the jet stream and associated waveguide is shown in terms of the 200-hPa geostrophic zonal wind in Fig. 11 and its meridional second derivative in Fig. 12-the contribution of the zonal wind to the potential vorticity gradient, the restoring force for Rossby waves. (The height field for each model has been regridded to $2.5^{\circ} \times 2.5^{\circ}$ resolution before calculating the geostrophic wind, to be consistent with the spatial scales of quasigeostrophy.) There are substantial differences between the model simulations in terms of both structure and magnitude, especially away from the core of the jet. While the overall fidelity of the teleconnection is not expected to depend only on the representation of the jet stream, the model with the most realistic jet stream, MIROC6, has one of the strongest correlations to SW Asian precipitation, while the model with the least realistic jet stream, GISS-E2-1-H, has one of the weaker correlations to SW Asian precipitation.

\section{f. Teleconnections to precipitation in the coastal Middle East and in northern Pakistan and India}

Finally, we consider the teleconnection in terms of two smaller regions on the margins of the strongest area of signal, the coastal Middle East on the western margin $\left(35^{\circ}-40^{\circ} \mathrm{E}, 30^{\circ}-\right.$ $\left.35^{\circ} \mathrm{N}\right)$ and northern Pakistan and India on the eastern margin $\left(70^{\circ}-80^{\circ} \mathrm{E}, 30^{\circ}-35^{\circ} \mathrm{N}\right)$. As the teleconnections are very similar to that for the SW Asia region, only the SST correlations are shown, although the correlations for the other variables may be found in the supplemental material.

For the coastal Middle East region, the observed SST correlations for the 1979-2014 period considered here (Fig. 13a) are very similar to those for SW Asia (Fig. 3a), albeit with somewhat smaller values of correlations in the Pacific and larger values in the Southern Ocean. As noted in the introduction, there is some question of how stable the observed relationship is, and there is evidence for other influences on this region as well, including from the NAO, so a greater range of behaviors in the model simulations might be expected. The model best-match SST correlations are shown in the other panels of Fig. 13 and, as before, all the models capture the very broadest aspect of the relationship-positive correlations in the central Pacific and negative correlations in the western Pacific - but with a wide range in the strength of the relationship between models. However, in this case of the coastal Middle East, none of the models fully reproduces the strength of the observed relationship, and the maximum correlations are less than for SW Asia.

The same analysis for the northern Pakistan and India region is shown in Fig. 14. The observed maximum SST correlations in the tropical Pacific are slightly less than for the coastal Middle East and occur farther to the east. As with the other regions, there is a wide range in the models' ability to reproduce the observed teleconnection. Four of the models (CESM2, CNRM-CM6-1, GISS-E2-1-H, MIROC6) have higher correlations for northern Pakistan and India than for the coastal Middle East, while two have lower correlations
(CanESM5, MPI-ESM1-2-HR). CESM2 has even higher correlations than the observations, the only occurrence of a model having notably higher correlations than observations in this analysis.

The results for these two regions highlight that, within the general geographic region of consideration, there are important variations both in the strength of the observed teleconnections and in the ability of different models to reproduce the observed teleconnections.

\section{Summary and discussion}

The ability of six CMIP6 models to reproduce the observed cold season teleconnection between tropical Indo-Pacific sea surface temperatures and precipitation in Southwest (SW) Asia, the coastal Middle East, and northern Pakistan and India was examined for the 1979-2014 period, using nine historical simulations for each model. We note that the results pertain to the specific versions of the models used here (see section 2 for more information) and may not be representative for other configurations or resolutions of the models. All six of the models capture the relationship to SW Asian precipitation in the broadest sense of having positive correlations to SSTs in the central equatorial Pacific and negative correlations in the western Pacific, but with a $40 \%$ difference among the models in the strength of the SST correlation. Only two of the models reproduce the magnitude of tropical SST influence consistent with observations and the pattern of SST correlations is different from observations for all models, based on a Monte Carlo significance assessment. Examination of the teleconnections to the adjacent regions of the coastal Middle East and northern Pakistan and India, which are very similar in structure, shows similar results, except that the models' ability to reproduce the strength and details of the teleconnection is generally even more limited.

The models' simulations of the regional seasonal cycles were also examined. The models generally capture the wet cold season-dry warm season distinction in both the SW Asia and coastal Middle East regions, but with some substantial differences from observations in both the timing and amplitude of the seasonal peak, as well as in overall precipitation amount. Several of the models have differences of more than a factor of 2 from the observed climatology for individual months. The region of northern Pakistan and India appears to be the most challenging for simulation, with none of the models capturing the observed ratio of warm season to cold season precipitation, and two of the models failing to reproduce any summer monsoon signal at all. These limitations in historical runs for both representation of the seasonal cycle and the leading teleconnection dictate that considerable caution needs to be applied to assessing precipitation projections in these regions.

The difficulties in reproducing the full teleconnection appear related to both the models' ability to capture the details of the tropical variability, including the position and strength of the precipitation anomalies in the Indo-west Pacific, and the models' ability to accurately propagate the response to the tropical convection into the region. Examination of the regional jet stream and associated waveguide show some model 
a) OBS

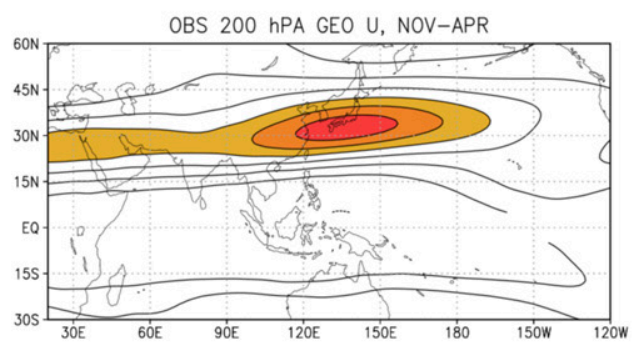

\section{b) CanESM5}

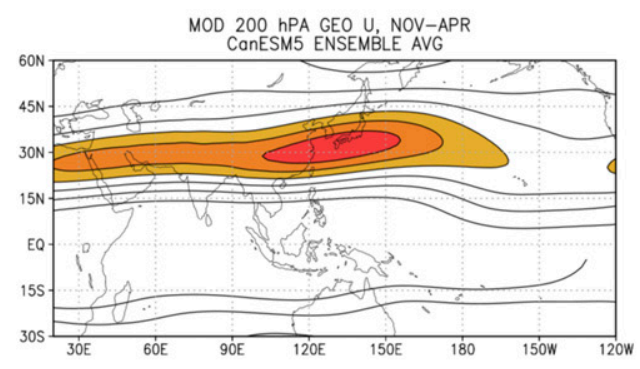

\section{c) CESM2}

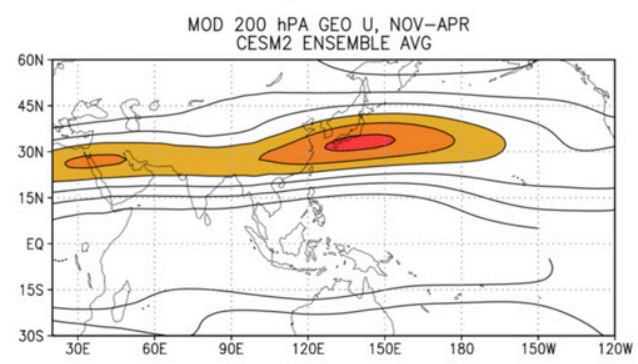

\section{d) CNRM-CM6-1}

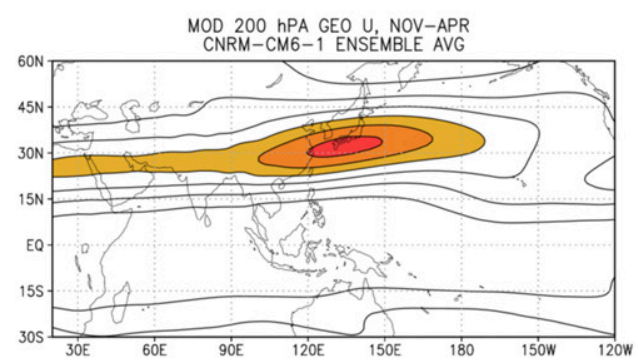

\section{e) GISS-E2-1-H}

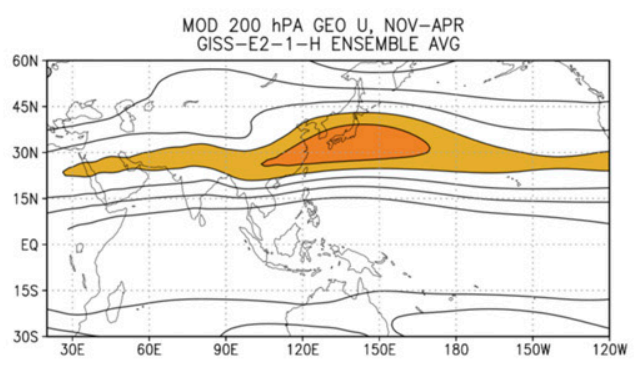

\section{f) MIROC6}

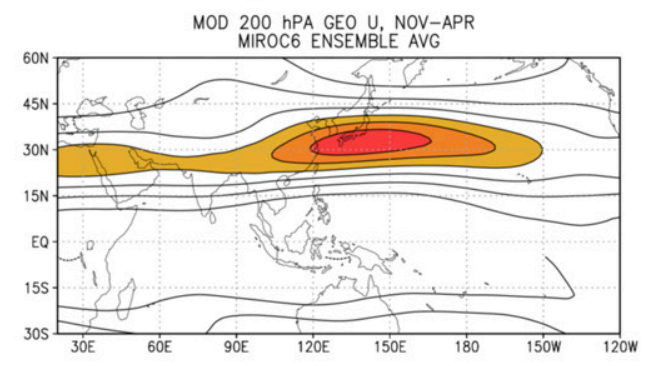

\section{g) MPI-ESM1-2-HR}

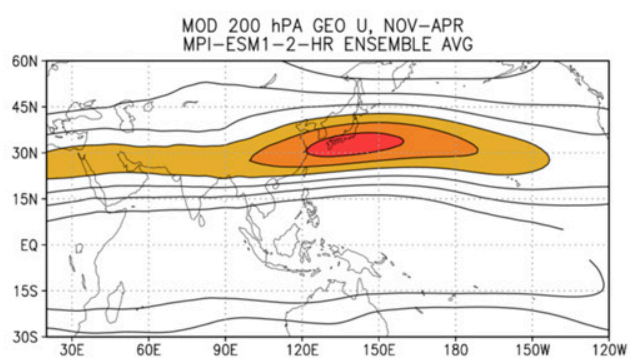

FIG. 11. Model-observation comparison of upper-level zonal wind. The seasonal mean November-April 200-hPa geostrophic zonal wind is shown for (a) observations and (b)-(g) models. The contour interval is $10 \mathrm{~m} \mathrm{~s}^{-1}$, and values above $40 \mathrm{~m} \mathrm{~s}^{-1}$ are shaded. 


\section{a) OBS}

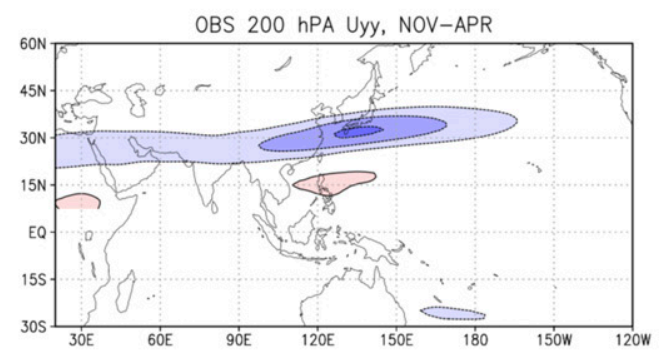

\section{b) CanESM5}

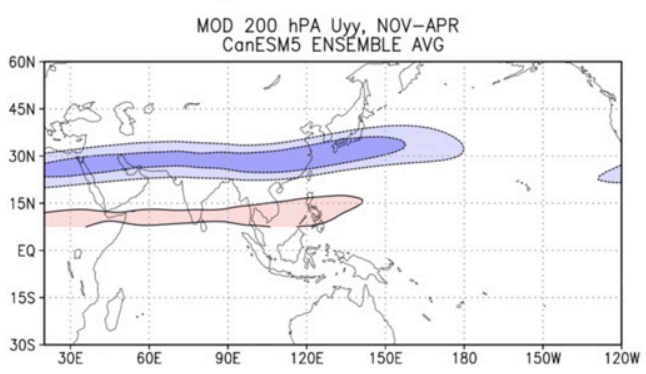

\section{c) CESM2}

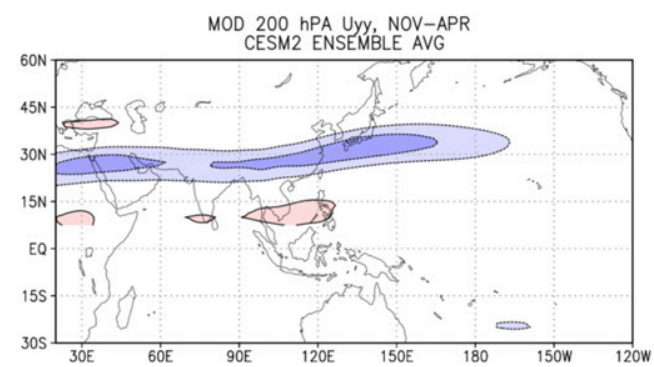

d) CNRM-CM6-1

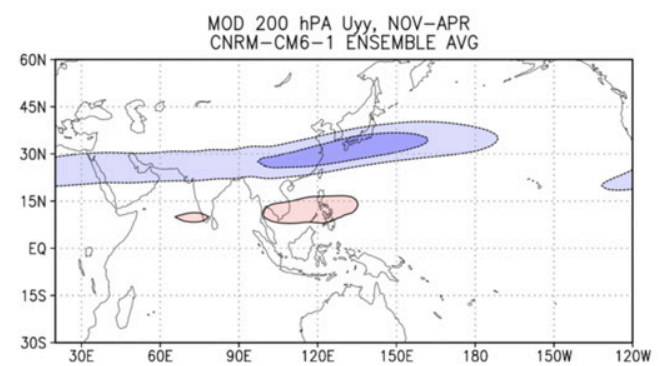

e) GISS-E2-1-H

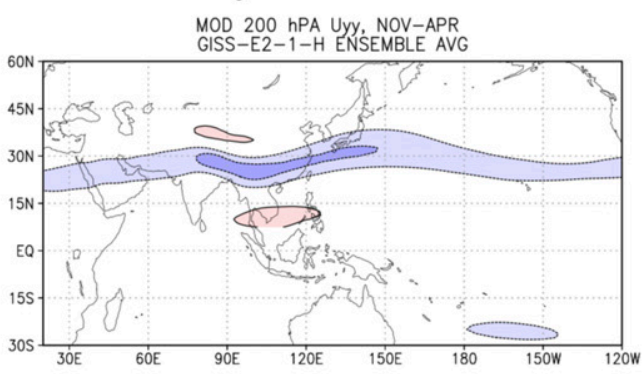

f) MIROC6

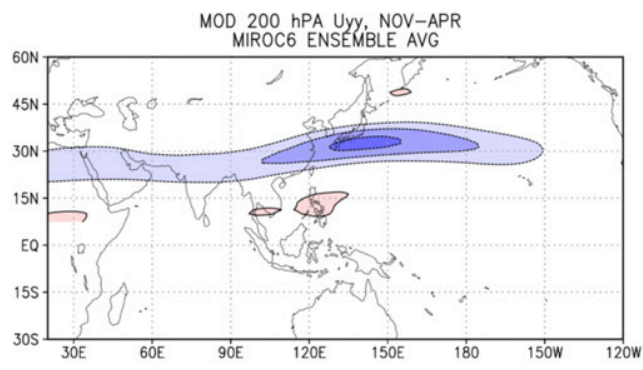

g) MPI-ESM1-2-HR

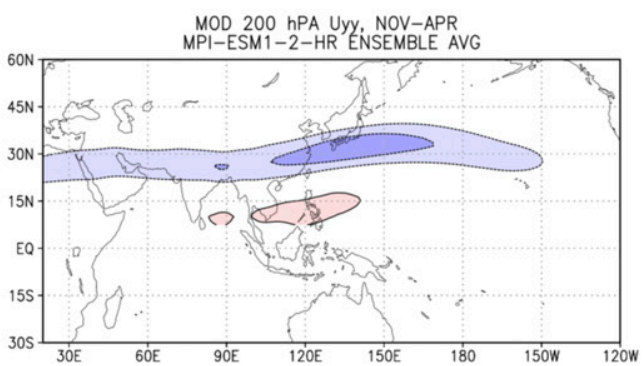

FIG. 12. Model-observation comparison of waveguide. The waveguide is estimated in terms of $U_{y y}$, using the geostrophic wind. Values are shown for (a) observations and (b) $-(\mathrm{g})$ models. The contour interval is $2 \times$ $10^{-11} \mathrm{~m}^{-1} \mathrm{~s}^{-1}$. 


\section{a) OBS}

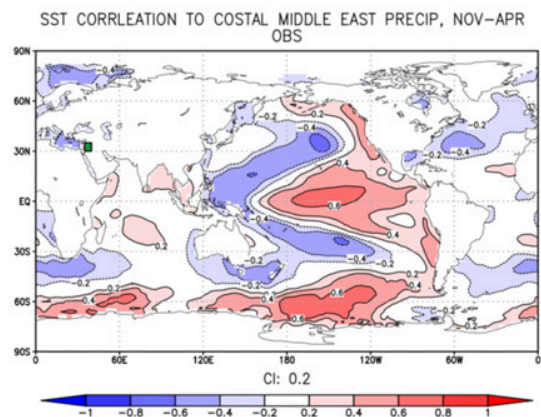

\section{b) CanESM5}

SST CORRELATION TO COASTAL ME PRECIP, NOV-APR

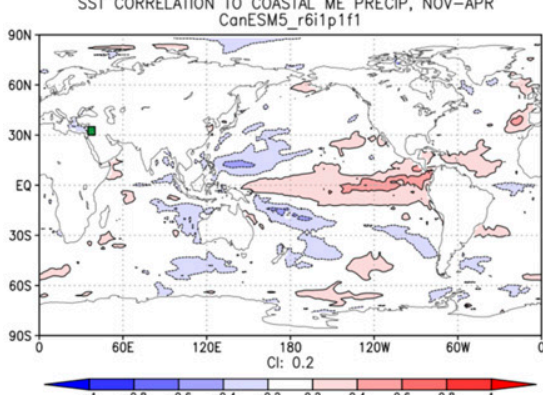

\section{c) CESM2}

SST CORRELATION TO COASTAL ME, PRECIP, NOV-APR

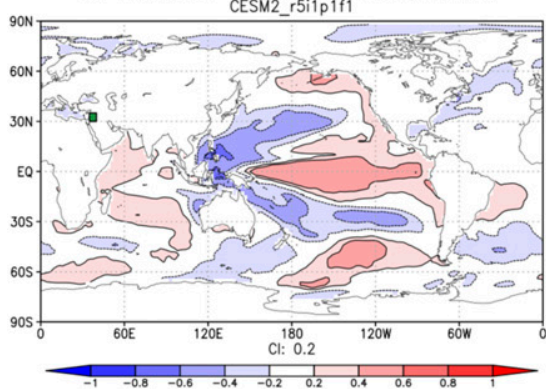

d) CNRM-CM6-1

SST CORRELATION TO COASTAL ME PRECIP, NOV-APR

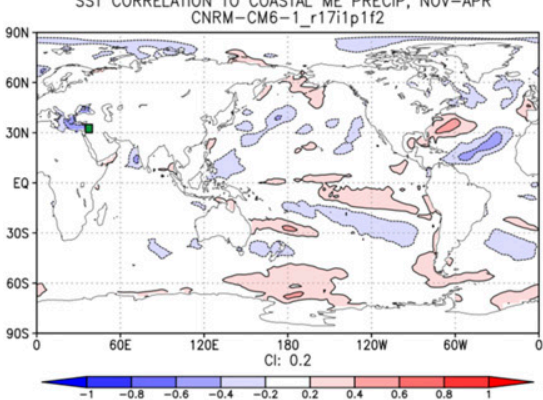

e) GISS-E2-1-H

SST CORRELATION TO COASTAL ME PRECIP, NOV-APR

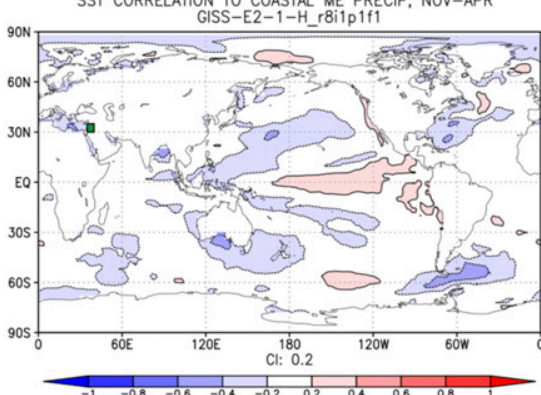

f) MIROC6

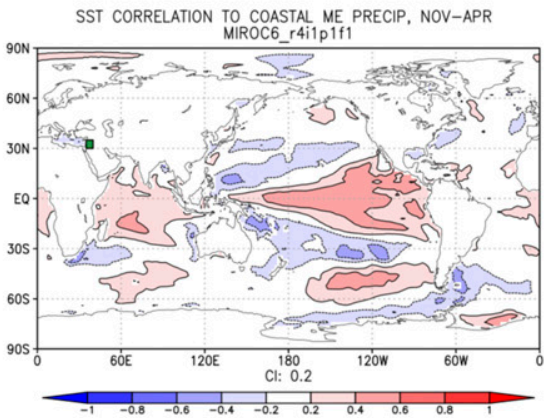

g) MPI-ESM1-2-HR

SST CORRELATION TO COASTAL ME PRECIP, NOV-APR

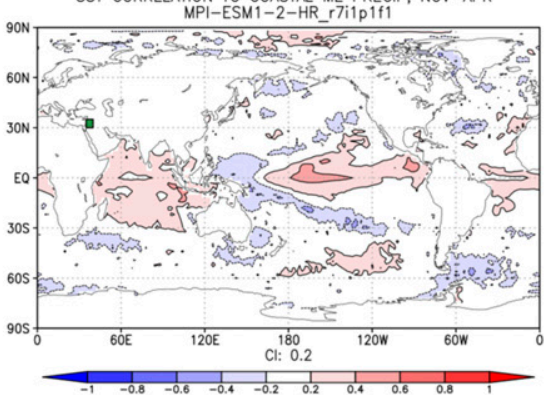

FIG. 13. Model-observation comparison for SSTs: coastal Middle East $\left(35^{\circ}-40^{\circ} \mathrm{E}, 30^{\circ}-35^{\circ} \mathrm{N}\right)$. SST correlations to the coastal Middle East precipitation are shown for (a) observations and (b)-(g) models. For each model, the simulation (out of nine, for each model) with the closest match is shown. The contour interval is 0.2 . 


\section{a) OBS}

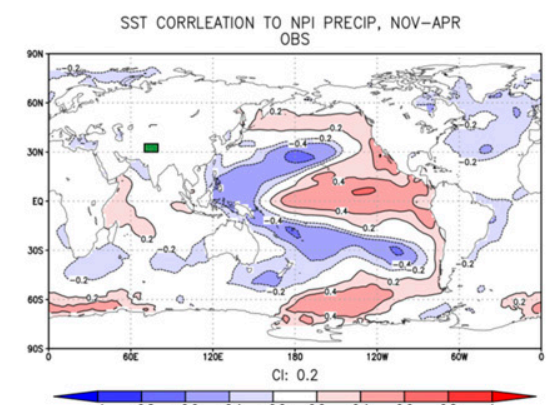

\section{b) CanESM5}

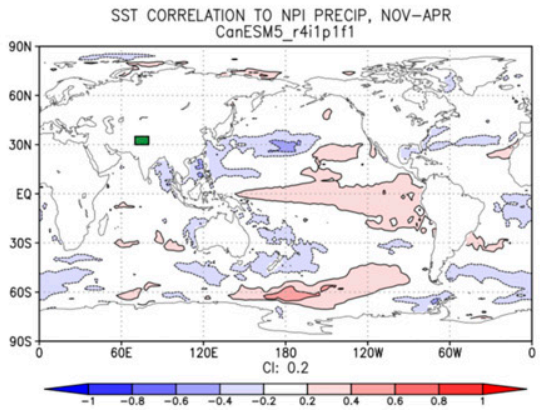

\section{c) CESM2}

SST CORRELATION TO NPI PRECIP, NOV-APR

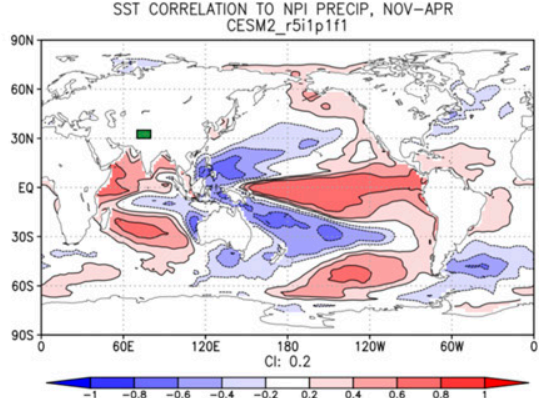

d) CNRM-CM6-1

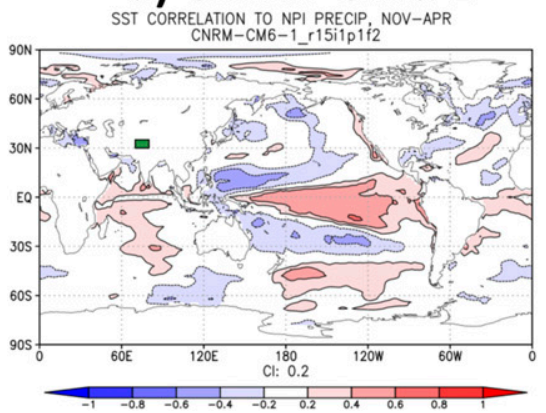

e) GISS-E2-1-H

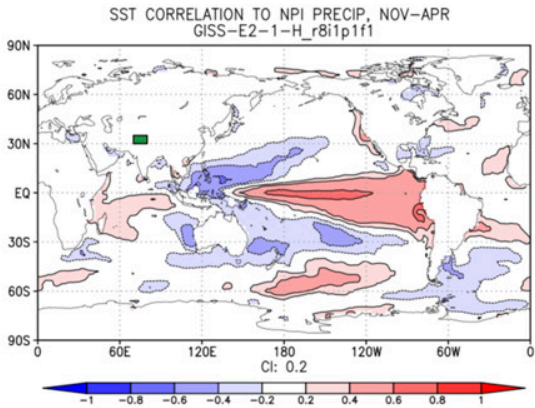

f) MIROC6

SST CORRELATION TO NPI PRECIP, NOV-APR

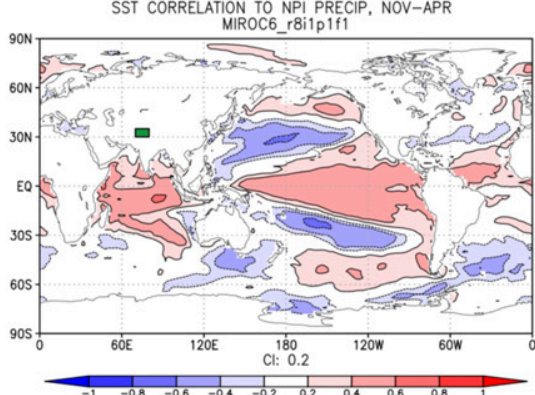

g) MPI-ESM1-2-HR

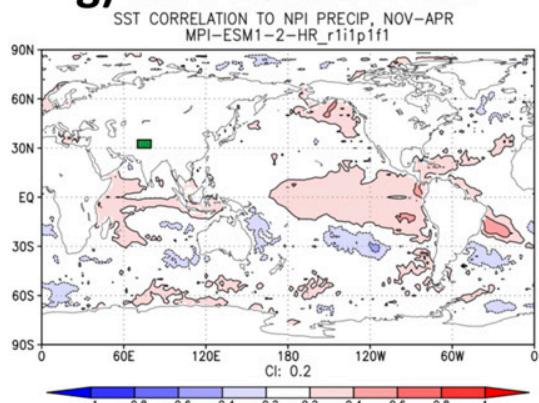

FIG. 14. Model-observation comparison for SSTs: northern Pakistan and India $\left(70^{\circ}-80^{\circ} \mathrm{E}, 30^{\circ}-35^{\circ} \mathrm{N}\right)$. SST correlations to the northern Pakistan and India precipitation are shown for (a) observations and (b)-(g) models. For each model, the simulation (out of nine, for each model) with the closest match is shown. The contour interval is 0.2 . 
limitations that may affect the propagation of the tropical response into the region.

This initial assessment of CMIP6 models for the regions raises a number of questions that, given the importance of precipitation in these very water-stressed regions, merit further attention. We plan to further investigate the relative roles of reproducing the tropical SST variability and reproducing the response by considering AMIP simulations, as available, for the atmospheric components of the models, as well as with linear model analysis, which can examine the response to the same tropical heating anomalies within different mean states as well to different tropical heating anomalies within the same mean state. Additionally, the analysis here has implicitly treated the ENSO phases as symmetric by considering correlations and regressions; it would be useful to analyze the phases independently. In terms of projections, it would be interesting to see whether there were any characteristic differences in projections between models with better skill at reproducing the teleconnection compared to models with less skill, as well as to explore implications that changes of jet structure with climate change may affect future teleconnections to the region. As more CMIP6 simulations become available, it would be important context for projections to have as wide an assessment of model fidelity as possible, and with different configurations of the same model. Finally, in the historical record, it would be useful to further examine the pre-satellite-era teleconnections in a range of observational datasets to attempt to separate the relative roles of data quality and interdecadal variations in changes to teleconnection strength, and to provide more detailed local information than the broad, rectangular latitudelongitude regions used here for simplicity.

Acknowledgments. Support from NSF AGS-1623912 and the Famine Early Warning Systems Network is gratefully acknowledged. We also acknowledge the use of the IRI/LDEO Climate Data Library and the PCMDI/LLNL data portal, which were very helpful for obtaining data. We thank three anonymous reviewers for their input in improving the paper.

Data availability statement. All the data analyzed in this paper is publicly available. The observational data were obtained through the IRI/LDEO Climate Data Library (https:// iridl.ldeo.columbia.edu) and the CMIP6 model data were obtained through the PCMDI/LLNL portal (https://esgf-node.llnl.gov/ search/cmip6/).

\section{REFERENCES}

Abid, M. A., F. Kucharski, M. Almazroui, and I.-S. Kang, 2016: Interannual rainfall variability and ECMWF-Sys4-based predictability over the Arabian Peninsula winter monsoon region. Quart. J. Roy. Meteor. Soc., 142, 233-242, https://doi.org/10.1002/qj.2648.

— , M. Almazroui, F. Kucharski, E. O'Brien, and A. E. Yousef, 2018: ENSO relationship to summer rainfall variability and its potential predictability over Arabian Peninsula region. npj Climate Atmos. Sci., 1, 20171, https://doi.org/10.1038/s41612017-0003-7.

Adler, R. F., and Coauthors, 2003: The version-2 Global Precipitation Climatology Project (GPCP) monthly precipitation analysis (1979-present). J. Hydrometeor., 4, 1147-1167, https://doi.org/ 10.1175/1525-7541(2003)004<1147:TVGPCP > 2.0.CO;2.

Alizadeh-Choobari, O., P. Adibi, and P. Irannejad, 2018: Impact of the El Niño-Southern Oscillation on the climate of Iran using ERA-Interim data. Climate Dyn., 51, 2897-2911, https:// doi.org/10.1007/s00382-017-4055-5.

Al Senafi, F., and A. Anis, 2015: Shamals and climate variability in the Northern Arabian/Persian Gulf from 1973 to 2012. Int. J. Climatol., 35, 4509-4528, https://doi.org/10.1002/joc.4302.

Athar, H., 2015: Teleconnections and variability in observed rainfall over Saudi Arabia during 1978-2010. Atmos. Sci. Lett., 16, 373-379, https://doi.org/10.1002/as12.570.

Atif, R. M., M. Almazroui, S. Saeed, M. Adnan Abid, N. Islam, and M. Ismail, 2019: Extreme precipitation events over Saudi Arabia during the wet season and their associated teleconnections. Atmos. Res., 231, 104655, https://doi.org/10.1016/ J.ATMOSRES.2019.104655.

Barlow, M., 2012: Africa and West Asia. Intraseasonal Variability in the Coupled Tropical Ocean-Atmosphere System, 2nd ed., W. Lau and D. Waliser, Eds., Praxis, 477-494.

_- and M. Tippett, 2008: Variability and predictability of central Asia river flows: Antecedent winter precipitation and largescale teleconnections. J. Hydrometeor., 9, 1334-1349, https:// doi.org/10.1175/2008JHM976.1.

_, and A. Hoell, 2015: Drought in the Middle East and centralsouthwest Asia during winter 2013/2014 [in "Explaining Extreme Events of 2014 from a Climate Perspective"]. Bull. Amer. Meteor. Soc., 96 (12), S71-S76, https://doi.org/10.1175/ BAMS-ExplainingExtremeEvents2014.1.

— , H. Cullen, and B. Lyon, 2002: Drought in central and Southwest Asia: La Niña, the warm pool, and Indian Ocean precipitation. J. Climate, 15, 697-700, https://doi.org/10.1175/ 1520-0442(2002)015<0697:DICASA > 2.0.CO;2.

- A. Hoell, and F. Colby, 2007: Examining the wintertime response to tropical convection over the Indian Ocean by modifying convective heating in a full atmospheric model. Geophys. Res. Lett., 34, L19702, https://doi.org/10.1029/2007GL030043.

—, B. Zaitchik, S. Paz, E. Black, J. Evans, and A. Hoell, 2016: A review of drought in the Middle East and Southwest Asia. J. Climate, 29, 8547-8574, https://doi.org/10.1175/JCLI-D-1300692.1.

Black, E., 2012: The influence of the North Atlantic Oscillation and European circulation regimes on the daily to interannual variability of winter precipitation in Israel. Int. J. Climatol., 32, 1654-1664, https://doi.org/10.1002/joc.2383.

Cannon, F., L. M. V. Carvalho, C. Jones, A. Hoell, J. Norris, G. N. Kiladis, and A. A. Tahir, 2017: The influence of tropical forcing on extreme winter precipitation in the western Himalaya. Climate Dyn., 48, 1213-1232, https://doi.org/10.1007/ s00382-016-3137-0.

Cullen, H. M., A. Kaplan, P. A. Arkin, and P. B. deMenocal, 2002: Impact of the North Atlantic Oscillation on Middle Eastern climate and streamflow. Climatic Change, 55, 315-338, https:// doi.org/10.1023/A:1020518305517.

Danabasoglu, G., and Coauthors, 2020: The Community Earth System Model version 2 (CESM2). J. Adv. Model. Earth Syst., 12, e2019MS001916, https://doi.org/10.1029/2019MS001916.

Donat, M. G., and Coauthors, 2014: Changes in extreme temperature and precipitation in the Arab region: Long-term trends and variability related to ENSO and NAO. Int. J. Climatol., 34, 581-592, https://doi.org/10.1002/joc.3707.

Eyring, V., S. Bony, G. A. Meehl, C. A. Senior, B. Stevens, R. J. Stouffer, and K. E. Taylor, 2016: Overview of the Coupled 
Model Intercomparison Project Phase 6 (CMIP6) experimental design and organization. Geosci. Model Dev., 9, 19371958, https://doi.org/10.5194/gmd-9-1937-2016.

Gerlitz, L., E. Steirou, C. Schneider, V. Moron, S. Vorogushyn, and B. Merz, 2018: Variability of the cold season climate in central Asia. Part I: Weather types and their tropical and extratropical drivers. J. Climate, 31, 7185-7207, https://doi.org/10.1175/JCLI-D-17-0715.1.

$\_,-, \ldots, \ldots, \ldots$, and — $\_, 2019$ : Variability of the cold season climate in central Asia. Part II: Hydroclimatic predictability. J. Climate, 32, 6015-6033, https://doi.org/10.1175/ JCLI-D-18-0892.1.

Gill, A. E., 1980: Some simple solutions for heat-induced tropical circulation. Quart. J. Roy. Meteor. Soc., 106, 447-462, https:// doi.org/10.1002/qj.49710644905.

Gutjahr, O., D. Putrasahan, K. Lohmann, J. H. Jungclaus, J.-S. von Storch, N. Brüggemann, H. Haak, and A. Stössel, 2019: Max Planck Institute Earth System Model (MPI-ESM1.2) for the High-Resolution Model Intercomparison Project (HighResMIP). Geosci. Model Dev., 12, 3241-3281, https://doi.org/10.5194/gmd-123241-2019.

Hoell, A., and C. Funk, 2013: The ENSO-related west Pacific sea surface temperature gradient. J. Climate, 26, 9545-9562, https://doi.org/10.1175/JCLI-D-12-00344.1.

_-, M. Barlow, and R. Saini, 2012: The leading pattern of intraseasonal and interannual Indian Ocean precipitation variability and its relationship with Asian circulation during the boreal cold season. J. Climate, 25, 7509-7526, https://doi.org/ 10.1175/JCLI-D-11-00572.1.

- _ - , and —, 2013: Intraseasonal and seasonal-tointerannual Indian Ocean convection and hemispheric teleconnections. J. Climate, 26, 8850-8867, https://doi.org/10.1175/ JCLI-D-12-00306.1.

— C. Cunk, and M. Barlow, 2014a: The regional forcing of Northern Hemisphere drought during recent warm tropical west Pacific Ocean La Niña events. Climate Dyn., 42, 32893311, https://doi.org/10.1007/s00382-013-1799-4.

,$- \ldots$, and $\_, 2014 \mathrm{~b}$ : La Niña diversity and northwest Indian Ocean rim teleconnections. Climate Dyn., 43, 27072724, https://doi.org/10.1007/s00382-014-2083-y.

_- S. Shukla, M. Barlow, F. Cannon, C. Kelley, and C. Funk, 2015a: The forcing of monthly precipitation variability over Southwest Asia during the boreal cold season. J. Climate, 28, 7038-7056, https://doi.org/10.1175/JCLI-D-14-00757.1.

_ C. Funk, and M. Barlow, 2015b: The forcing of southwestern Asia teleconnections by low-frequency sea surface temperature variability during boreal winter. J. Climate, 28, 1511-1526, https://doi.org/10.1175/JCLI-D-14-00344.1.

— - M. Barlow, F. Cannon, and T. Xu, 2017a: Oceanic origins of historical Southwest Asia precipitation during the boreal cold season. J. Climate, 30, 2885-2903, https://doi.org/10.1175/ JCLI-D-16-0519.1.

—, C. Funk, M. Barlow, and F. Cannon, 2017b: A physical model for extreme drought over Southwest Asia. Climate Extremes, John Wiley \& Sons, 283-298.

—, M. Barlow, T. Xu, and T. Zhang, 2018: Cold season Southwest Asia precipitation sensitivity to El Niño-Southern Oscillation events. J. Climate, 31, 4463-4482, https://doi.org/ 10.1175/JCLI-D-17-0456.1.

Hoerling, M., and A. Kumar, 2003: The perfect ocean for drought. Science, 299, 691-694, https://doi.org/10.1126/science.1079053.

Hoskins, B. J., and T. Ambrizzi, 1993: Rossby wave propagation on a realistic longitudinally varying flow. J. Atmos. Sci., 50,
1661-1671, https://doi.org/10.1175/1520-0469(1993)050<1661: RWPOAR $>2.0 . \mathrm{CO} ; 2$.

Huang, B., and Coauthors, 2017: Extended Reconstructed Sea Surface Temperature, version 5 (ERSSTv5): Upgrades, validations, and intercomparisons. J. Climate, 30, 8179-8205, https://doi.org/ 10.1175/JCLI-D-16-0836.1.

Kalnay, E., and Coauthors, 1996: The NCEP/NCAR 40-Year Reanalysis Project. Bull. Amer. Meteor. Soc., 77, 437-471, https://doi.org/ 10.1175/1520-0477(1996)077<0437:TNYRP>2.0.CO;2.

Kamil, S., M. Almazroui, I. S. Kang, M. Hanif, F. Kucharski, M. A. Abid, and F. Saeed, 2019: Long-term ENSO relationship to precipitation and storm frequency over western HimalayaKarakoram-Hindukush region during the winter season. Climate Dyn., 53, 5265-5278, https://doi.org/10.1007/s00382019-04859-1.

Kang, I. S., I. U. Rashid, F. Kucharski, M. Almazroui, and A. K. Alkhalaf, 2015: Multidecadal changes in the relationship between ENSO and wet-season precipitation in the Arabian Peninsula. J. Climate, 28, 4743-4752, https://doi.org/10.1175/ JCLI-D-14-00388.1.

Kelley, M., and Coauthors, 2020: GISS-E2.1: Configurations and climatology. J. Adv. Model. Earth Syst., 12, e2019MS002025, https://doi.org/10.1029/2019MS002025.

Mann, M. E., 2002: Large-scale climate variability and connections with the Middle East in past centuries. Climatic Change, 55, 287-314, https://doi.org/10.1023/A:1020582910569.

Mariotti, A., 2007: How ENSO impacts precipitation in southwest central Asia. Geophys. Res. Lett., 34, L16706, https://doi.org/ 10.1029/2007GL030078.

_ J. Ballabrera-Poy, and N. Zeng, 2005: Tropical influence on Euro-Asian autumn rainfall variability. Climate Dyn., 24, 511521, https://doi.org/10.1007/s00382-004-0498-6.

Matsuno, T., 1966: Quasi-geostrophic motions in the equatorial area. J. Meteor. Soc. Japan, 44, 25-43, https://doi.org/10.2151/ JMSJ1965.44.1_25.

Nazemosadat, M. J., and A. R. Ghasemi, 2004: Quantifying the ENSO-related shifts in the intensity and probability of drought and wet periods in Iran. J. Climate, 17, 40054018, https://doi.org/10.1175/1520-0442(2004)017<4005: QTESIT $>2.0 . \mathrm{CO} ; 2$.

Niranjan Kumar, K., and T. B. M. J. Ouarda, 2014: Precipitation variability over UAE and global SST teleconnections. J. Geophys. Res. Atmos., 119, 10313-10322, https://doi.org/ 10.1002/2014JD021724.

_ _ _ S. Sandeep, and R. S. Ajayamohan, 2016: Wintertime precipitation variability over the Arabian Peninsula and its relationship with ENSO in the CAM4 simulations. Climate Dyn., 47, 2443-2454, https://doi.org/10.1007/s00382016-2973-2.

Price, C., L. Stone, A. Huppert, B. Rajagopalan, and P. Alpert, 1998: A possible link between El Niño and precipitation in Israel. Geophys. Res. Lett., 25, 3963-3966, https://doi.org/ 10.1029/1998GL900098.

Rana, S., J. McGregor, and J. Renwick, 2017: Wintertime precipitation climatology and ENSO sensitivity over central southwest Asia. Int. J. Climatol., 37, 1494-1509, https://doi.org/ 10.1002/joc. 4793 .

,-- , and -2019 : Dominant modes of winter precipitation variability over central Southwest Asia and inter-decadal change in the ENSO teleconnection. Climate Dyn., 53, 56895707, https://doi.org/10.1007/s00382-019-04889-9.

Sardeshmukh, P. D., and B. J. Hoskins, 1988: The generation of global rotational flow by steady idealized tropical divergence. 
J. Atmos. Sci., 45, 1228-1251, https://doi.org/10.1175/15200469(1988)045<1228:TGOGRF $>2.0$. CO; 2 .

Shaman, J., and E. Tziperman, 2005: The effect of ENSO on Tibetan Plateau snow depth: A stationary wave teleconnection mechanism and implications for the South Asian monsoons. J. Climate, 18, 2067-2079, https://doi.org/10.1175/JCLI3391.1.

Soltani, M., and Coauthors, 2016: Assessment of climate variations in temperature and precipitation extreme events over Iran. Theor. Appl. Climatol., 126, 775-795, https://doi.org/10.1007/ s00704-015-1609-5.

Swart, N. C., and Coauthors, 2019: The Canadian Earth System Model version 5 (CanESM5.0.3). Geosci. Model Dev., 12, 4823-4873, https://doi.org/10.5194/gmd-12-4823-2019.

Syed, F. S., F. Giorgi, J. S. Pal, and M. P. King, 2006: Effect of remote forcings on the winter precipitation of central Southwest Asia. Part I: Observations. Theor. Appl. Climatol., 86, 147-160, https://doi.org/10.1007/s00704-005-0217-1.

Tatebe, H., and Coauthors, 2019: Description and basic evaluation of simulated mean state, internal variability, and climate sensitivity in MIROC6. Geosci. Model Dev., 12, 2727-2765, https://doi.org/10.5194/gmd-12-2727-2019.
Ting, M., and P. D. Sardeshmukh, 1993: Factors determining the extratropical response to equatorial diabatic heating anomalies. J. Atmos. Sci., 50, 907-918, https://doi.org/10.1175/1520-0469(1993) 050<0907:FDTERT>2.0.CO;2.

— linear and nonlinear baroclinic models. J. Atmos. Sci., 55, 3565-3582, https://doi.org/10.1175/1520-0469(1998)055<3565: SRTTHI $>2.0 . \mathrm{CO} ; 2$.

Vigaud, N., M. Tippett, and A. Robertson, 2018: Probabilistic skill of subseasonal precipitation forecasts for the East Africa-West Asia sector during September-May. Wea. Forecasting, 33, 15131532, https://doi.org/10.1175/WAF-D-18-0074.1.

Voldoire, A., and Coauthors, 2019: Evaluation of CMIP6 DECK experiments with CNRM-CM6-1. J. Adv. Model. Earth Syst., 11, 2177-2213, https://doi.org/10.1029/2019MS001683.

Yadav, R. K., K. Rupa Kumar, and M. Rajeevan, 2009: Increasing influence of ENSO and decreasing influence of AO/NAO in the recent decades over northwest India winter precipitation. J. Geophys. Res., 114, D12112, https://doi.org/10.1029/ 2008JD011318. 